\title{
Thalamostriatal degeneration contributes to dystonia and cholinergic interneuron dysfunction in a mouse model of Huntington's disease
}

\author{
Gabriel Crevier-Sorbo, Vladimir V. Rymar, Raphael Crevier-Sorbo and Abbas F. Sadikot
}

\begin{abstract}
Huntington's disease (HD) is an autosomal dominant trinucleotide repeat disorder characterized by choreiform movements, dystonia and striatal neuronal loss. Amongst multiple cellular processes, abnormal neurotransmitter signalling and decreased trophic support from glutamatergic cortical afferents are major mechanisms underlying striatal degeneration. Recent work suggests that the thalamostriatal (TS) system, another major source of glutamatergic input, is abnormal in HD although its phenotypical significance is unknown. We hypothesized that TS dysfunction plays an important role in generating motor symptoms and contributes to degeneration of striatal neuronal subtypes. Our results using the R6/2 mouse model of HD indicate that neurons of the parafascicular nucleus (PF), the main source of TS afferents, degenerate at an early stage. PF lesions performed prior to motor dysfunction or striatal degeneration result in an accelerated dystonic phenotype and are associated with premature loss of cholinergic interneurons. The progressive loss of striatal medium spiny neurons and parvalbumin-positive interneurons observed in R6/2 mice is unaltered by PF lesions. Early striatal cholinergic ablation using a mitochondrial immunotoxin provides evidence for increased cholinergic vulnerability to cellular energy failure in R6/2 mice, and worsens the dystonic phenotype. The TS system therefore contributes to trophic support of striatal interneuron subtypes in the presence of neurodegenerative stress, and TS deafferentation may be a novel cell non-autonomous mechanism contributing to the pathogenesis of HD. Furthermore, behavioural experiments demonstrate that the TS system and striatal cholinergic interneurons are key motor-network structures involved in the pathogenesis of dystonia. This work suggests that treatments aimed at rescuing the TS system may preserve important elements of striatal structure and function and provide symptomatic relief in HD.
\end{abstract}

Keywords: Parafascicular, Striatum, Thalamus, R6/2, Basal ganglia, Immunotoxin

\section{Introduction}

Huntington's disease (HD) is a progressive autosomal dominant neurodegenerative disorder characterized by choreiform movements, dystonia and psychiatric symptoms $[1,2]$. $\mathrm{HD}$ is caused by an abnormal expansion of CAG trinucleotides in exon 1 of the huntingtin gene ( $m h t t)$ with larger numbers of repeats leading to earlier age of onset and more severe symptoms [3]. Despite ubiquitous expression of $m h t t$, medium spiny projection neurons (MSNs) of the striatum are a major target for degeneration [2]. Interneurons, which comprise a small proportion of all striatal neurons,

\footnotetext{
* Correspondence: abbas.sadikot@mcgill.ca

Department of Neurology and Neurosurgery, Montreal Neurological Institute, McGill University, 3801 University street, H3A 2B4, Montreal, Quebec, Canada
}

were initially thought to be spared in HD [4]. However recent work suggests that the density of GABAergic parvalbu$\min (\mathrm{PV})$ positive [5] and cholinergic interneuron subtypes are reduced in HD [6] with relative sparing of other interneuron groups [5-7]. Multiple pathophysiological mechanisms may explain the predilection for striatal neuronal loss including: hyperexcitability, loss of afferent-derived trophic support, immune cell activation, and diverse intracellular signaling abnormalities [8-16].

Loss of afferent-mediated trophic support contributes to neuronal loss in common neurodegenerative diseases, including Alzheimer's disease [17, 18] and Parkinson's disease [19-21]. Trophic support from the major glutamatergic striatal afferent systems may also play an important role in 
HD. In vivo imaging and autopsy studies suggest that the cerebral cortex atrophies in prodromal HD along with the striatum, and this atrophy is severe by late stages $[2,22]$. Recent MRI studies indicate that the thalamus also undergoes significant atrophy in early disease [23]. Post-mortem analysis indicates that the posterior intralaminar thalamus, or centromedian-parafascicular (CM-PF) complex, is an important target for degeneration in HD [24].

The CM-PF in primates or the parafascicular (PF) in rodents is a major source of glutamatergic afferents to the striatum, specifically targeting MSNs of the matrix subcompartment of the neostriatal mosaic [25-27]. The PF also provides dense input to two major striatal interneuron subtypes implicated in HD: the cholinergic and PV positive interneurons [28-30]. Recent ultrastructural studies in the heterozygous Q140 mouse model of HD suggest early pathology in the thalamostriatal (TS) projection prior to corticostriatal degeneration [31, 32]. Further experiments show coexistent ultrastructural pathology of striatal cholinergic interneurons at early time-points in Q140 mice [31].

In order to determine whether thalamic inputs to the striatum play a critical role in survival of striatal neurons and in development of motor dysfunction in HD, we assessed the structural and functional effects of early PF lesions in an animal model of HD. We used the R6/2 model, a transgenic mouse with approximately 125 CAG repeats in the N-terminal portion of the mhtt gene [33]. The R6/2 mouse is a well-studied model and reproduces many of the motor and morphological features of HD [34]. Our results provide evidence for early degeneration of PF neurons prior to striatal neuron loss in the R6/2 model. Early lesions of the TS in R6/2 mice result in an acceleration of clasping movements suggesting worsened dystonic behaviour. PF lesions do not accelerate the time course of progressive loss of spontaneous locomotion in an open field during the R6/2 lifespan. PF lesioned mice regardless of genotype show decreased exploration using the contralateral forelimb. Morphological analysis indicates that PF lesions do not alter the extent of degeneration of striatal projection neurons and PV neurons in R6/ 2 mice. In contrast, TS lesions in R6/2 mice lead to early degeneration of striatal cholinergic neurons. Finally, early unilateral striatal cholinergic ablation in R6/2 mice using cell-specific immunotoxins also leads to an increase in clasping suggesting an important link between TS inputs to cholinergic neurons and dystonia in HD.

\section{Materials and methods}

\section{Animals}

The behavioural experiments were performed using R6/2 mice and WT littermate mice from a colony maintained at the Facility for Neurological Disease Models of the Montreal Neurological Institute. Ovarian transplanted R6/ 2 females were obtained from a line maintained at The
Jackson Laboratory and were crossed with males of the C57BL6J background. CAG repeat lengths were sequenced and found to be between 119 and 125 for R6/2 mice and normal for WT littermates.

\section{Surgery and lesion verification}

All surgical procedures were performed in accordance with the Standard Operating Procedures (SOPs) for stereotaxic mouse surgery at McGill University. Twentyeight day-old mice were anaesthetized using a ketamine and xylazine (Rompun, Bayer, USA) cocktail. Stereotactic lesions were made at coordinates corresponding to the PF (Bregma $-2.20 \mathrm{~mm},-3.3 \mathrm{~mm}$ below the cortical surface, and $0.6 \mathrm{~mm}$ lateral to midline) [35]. A loop-shaped retractable leucotome [36] was inserted to the level of the $\mathrm{PF}$, deployed to a radius of $0.5 \mathrm{~mm}$, rotated twice, closed and then retracted. Sham-lesioned animals underwent the same procedure except the leucotome was inserted 2.5 $\mathrm{mm}$ beneath the cortical surface but not deployed. Lesions were verified on Nissl stain or Nissl-NeuN using the 4X objective and the extent of each lesion was analyzed on images captured on tiled images (StereoInvestigator (v10, Microbrightfield, USA). Mice with lesions that either crossed the midline or with large lesions extending beyond the PF into the ventral thalamus were excluded.

\section{Saporin injection and verification of effects in striatum}

Use of anti-ChAT conjugated saporin toxins are welldescribed for selectively ablating cholinergic interneurons in the rodent striatum [37]. Using the same stereotactic techniques mentioned above, 28-day-old R6/2 and WT mice underwent unilateral, striatal injections with either anti-ChAT-saporin or Rabbit IgG-saporin (ATS BIO, USA). The total volume and concentration of either saporin construct was the same $(0.7 \mu \mathrm{L}$ of $0.6 \mu \mathrm{g} / \mu \mathrm{L}$ solution). The approximate center of mass of the neostriatum was targeted $(0.65 \mathrm{~mm}$ from Bregma, $2.6 \mathrm{~mm}$ from the cortical surface and $2.15 \mathrm{~mm}$ lateral to midline) [35]. The toxin was infused at a rate of $0.1 \mu \mathrm{L} /$ minute using an automated system (Pump 11 Elite, Harvard Apparatus, USA) through a $5 \mu \mathrm{L}$ syringe (Hamilton 700 series, USA). Histological sections were immunostained for ChAT protein and counterstained with cresyl violet allowing visualization of the needle tract, confirming injection placement in the neostriatum, and allowing unbiased stereological analysis of striatal cholinergic cell morphology.

\section{Behavioural studies}

All behavioural testing was performed during the first five hours of the light phase in a standard 12-h lightdark cycle [38]. Tests were performed at 4, 6, 9 and 11 wks \pm 1 day (Additional file 1, Experimental Timeline), with the open field and cylinder test at day 1 , and the clasping test at day 2 [38]. 


\section{Spontaneous locomotion in open field}

Mice were placed in a four arena $50 X 50 \mathrm{~cm}$ open field with infrared backlighting for one-hour [34], and movements were videotaped using an overhead camera [39] and later analyzed using VideoTrack (Viewpoint, Montreal, Canada). Spontaneous voluntary locomotor activity was categorized as follows: inactivity or non-ambulatory movements $(<1 \mathrm{~cm} /$ second), moderate speed (between 1 and $5 \mathrm{~cm} /$ second) or fast speed ( $>5 \mathrm{~cm} /$ second).

\section{Vertical exploratory behaviour}

Mice were placed in a plexiglass cylinder (diameter 20 $\mathrm{cm}$, height $30 \mathrm{~cm}$ ) with two mirrors positioned behind the cylinder in order to ensure a 360-degree view of the animal's forelimb wall touches. The session was videorecorded and the number of vertical contacts on the cylinder wall with the right paw, left paw or both paws simultaneously were scored on frame by frame analysis with the viewer blind to operative status and genotype.

\section{Clasping score}

A tail suspension or clasping test was used to assess the development of dystonic forelimb contractions previously documented in the R6/2 mouse [14, 34]. Mice were suspended by the tail at a height of at least $30 \mathrm{~cm}$, for three trials lasting 30-s each, while limb movements were videotaped. Clasping was defined as a retraction of a limb toward the body. In order to provide a semi-quantitative index of abnormal involuntary movements, clasping at each limb was graded as: none $=0$, mild $=0.25$, moderate $=0.5$, severe $=0.75$ by an observer blind to genotype. Clasping was rated as: "none" if the mouse did not retract the limb towards the midline and "mild" if partial retraction of a limb occurred toward the midline but did not reach the midline, and the contraction was not sustained. "Moderate" clasping was a high-amplitude limb retraction to or beyond the midline that was not sustained, or partial limb retraction that was sustained for $\geq 5$ consecutive seconds. "Severe" clasping was a high-amplitude limb retraction to or beyond the midline sustained for $\geq 5 \mathrm{~s}$. The score for the forelimbs and hindlimbs was summed making the maximum score 3 . The average value of all three clasping trials was analyzed.

\section{Tissue processing}

R6/2 mice and WT mice were deeply anesthetized and perfused transcardially with $0.9 \%$ heparinized saline followed by $4 \%$ paraformaldehyde in phosphate buffer (4\% PFA) $(0.1 \mathrm{M}, \mathrm{pH} 7.4)$ both at $4{ }^{\circ} \mathrm{C}$. Brains were removed, fixed in $4 \%$ PFA for $24 \mathrm{~h}$ then transferred to a phosphate buffered 30\% sucrose solution for 24-48 h. Brains were sectioned at $40 \mu \mathrm{m}$ in the coronal plane with a freezing microtome. Free-floating sections were collected serially in six vials containing phosphate-buffered saline (PBS, $0.1 \mathrm{M}, \mathrm{pH} 7.4$ ). One set of sections was mounted out of distilled water onto glass slides, stained in $0.1 \%$ cresyl violet (Nissl stain) and coverslipped using Permount (Fisher Scientific, Whitby, ON, Canada). The remaining vials were immediately placed in buffered anti-freeze solution and stored at $-20^{\circ} \mathrm{C}$.

\section{Immunohistochemistry}

The following primary antibodies were used in these experiments: mouse anti- NeuN (Millipore, Etobicoke, Canada; MAB377, 1:1000), Rabbit anti- $\mu$-opioid receptor (Immunostar, Hudson, USA; \#24216; 1:8000), mouse anti-parvalbumin (Swant, Fribourg, Switzerland; \#235; 1: 5000) and rabbit anti-ChAT (Millipore; AB143; 1:600). Sections were removed from antifreeze, rinsed six times in PBS, and then incubated for one hour in a blocking solution (10\% bovine serum albumin (BSA), 0.3\% Triton-X, 0.1 M PBS, pH 7.4). Next the sections were incubated in primary antibody in PBS containing 0.1\% Triton-X and either 2\% BSA or 5\% NGS for 24-48 h at $4{ }^{\circ} \mathrm{C}$. After washes in PBS, sections were incubated in the following biotinylated secondary antibodies: horse antimouse IgG (Vector Laboratories, Burlingame, California, USA; BA-2000; 1:200), goat anti-rabbit IgG (Vector Laboratories; BA-1000; 1:200). Sections were washed once more in PBS and then incubated for $1 \mathrm{~h}$ in 1:100 ABC elite kit (PK6100, Vector Laboratories). Antibody binding was revealed using $0.05 \%$ 3,3'-diaminobenzidsine (D5905, Sigma-Aldrich, Oakville, ON, Canada) in TBS ( $\mathrm{pH}$ 7.6) and hydrogen peroxide (0.01\%). All slices were then mounted out of distilled water onto slides, counterstained with $0.1 \%$ cresyl violet and coverslipped using Permount (SP15, Fisher Scientific).

\section{Unbiased stereology}

An unbiased stereological probe, the optical fractionator [40], was used to estimate the number of neurons in the areas of interest. The stereology apparatus consisted of a light microscope (BX40, Olympus, Japan) coupled with a video camera (DC200, DAGE, USA), motorized X-Y stage (BioPoint XYZ, LEP, USA), Z-axis indicator (MT12 microcator, Germany), and a computer running Stereo Investigator software (v11.06.2, Microbrightfield, USA). The neostriatum was delineated according to previously defined boundaries [34] using the mouse brain atlas of Paxinos and Franklin [35] and a 4X objective. Rostral and caudal limits were determined by the first and last coronal sections with visible caudate-putamen (Bregma $1.7 \mathrm{~mm}$ to $-2.0 \mathrm{~mm}$ ) [35]. Every sixth serial histological section within this zone was examined ( $240 \mu \mathrm{m}$ intervals). The dorsal, medial and lateral limits of the neostriatum are well defined in the mouse brain atlas [35]. The ventral limit of the striatum at the postcommissural part is well delineated on Nissl stains. At 
the pre-commissural levels, we delimit the dorsal striatum from the nucleus accumbens with a line that extends from above the ventral most part of the lateral ventricle medially, to the tapered external capsule laterally, at an angle of $25-30^{\circ}$ below the axial plane [34, 41]. The PF was delineated using the same mouse brain atlas [35] using a 10X objective. All sections with a clearly distinguishable PF were delineated (Bregma - 2.0 $\mathrm{mm}$ to $-2.5 \mathrm{~mm}$ ) [35]. Every other section within the PF reference range was examined $(80 \mu \mathrm{m}$ intervals).

Systematic random sampling of neurons was performed by randomly translating a grid onto the section of interest. At each intersection of grid lines an optical fractionator counting frame with exclusion lines was applied. A $150 \times 150 \mu \mathrm{m}$ grid size and a $60 \times 60 \mu \mathrm{m}$ counting frame was used for the PF neuron optical fractionator analysis (Gunderson CE $(\mathrm{m}=1)=0.038 \pm 0.001)$. A $300 \mathrm{X} 300 \mu \mathrm{m}$ grid size and a $25 \times 25 \mu \mathrm{m}$ counting frame was used for optical fractionator analysis in the neostriatum (Gunderson $\mathrm{CE}(\mathrm{m}=1)=0.029 \pm 0.001)$. A $250 \mathrm{X} 250 \mu \mathrm{m}$ grid size and a $70 X 90 \mu \mathrm{m}$ counting frame was used for the parvalbumin interneuron optical fractionator analysis (Gunderson CE $(\mathrm{m}=1)=0.064 \pm 0.001)$. A $175 \times 175 \mu \mathrm{m}$ grid size and a $70 \times 90 \mu \mathrm{m}$ counting frame was used for the cholinergic interneuron optical fractionator analysis (Gunderson CE $(\mathrm{m}=1)=0.080 \pm 0.003)$. All randomly assigned sample sites were then examined using a 100X objective (oil; numerical aperture, 1.3). Section thickness was assessed every ten counting sites using the Z-axis indicator (MT12 microcator, Germany). The top of the neuron was used as a unique identifier in all analyses. Neurons falling in the counting frame were counted only if they came into focus within a predetermined $8-\mu \mathrm{m}$-thick optical dissector positioned 1- $\mu \mathrm{m}$ above and below the surface of the mounted section as indicated by the Z-axis indicator. For the neostriatal mosaic analysis, neurons were distinguished on Nissl-stains based on cell diameter $(>7 \mu \mathrm{m})$, and a lighter cytoplasm containing a dense nucleus [34].

Neuron soma area and volume of the PF and striatum were estimated using a four-ray nucleator probe [42] or the Cavalieri probe [40] respectively. For the Cavalieri probe, a grid of $40 \mathrm{X} 40 \mu \mathrm{m}$ squares was randomly translated over the delineated structures of interest and markers were placed at the intersection of grid lines that fell within the delineated structure. Estimates of the total number of neurons, soma area and Cavalieri volume were calculated by the Stereo Investigator software (v10, Microbrightfield, USA).

\section{Statistical analyses}

Normality was assessed prior to performing comparative tests using the Shapiro-Wilks test. An analysis of variance (ANOVA) was performed on normal data using the aov function in R [43]. Post hoc analysis of normal data consisted of a two-tailed, paired or unpaired t-test based on whether the samples were dependent or independent respectively. Post hoc tests on normal data were corrected for multiple comparisons using Tukey's Honestly Significant Difference test (HSD). A non-parametric ANOVA was performed on non-normally distributed data or ordinal data using the art function from the 'ARTool' package [44] in R. Post hoc analysis for nonparametric data included a two-tailed Mann-Whitney Utest or a Wilcoxon signed-rank test for independent and dependent samples respectively. Non-parametric post hoc tests were corrected for multiple comparisons using the Bonferroni correction. For behavioural tests, the main factors of the ANOVA were time as a withinsubject factor, and genotype and lesion status as between-subject factors. The main ANOVA factors for morphological studies, genotype and lesion status were analyzed as independent groups. All data are expressed as averages \pm standard error of the mean (SEM). The SEM is represented graphically as error bars. $P$-values $\leq 0.05$ were considered significant.

\section{Results}

\section{The PF degenerates in the $\mathrm{R} 6 / 2$ model of $\mathrm{HD}$}

To determine if the PF is susceptible to degeneration in $\mathrm{HD}$, we quantified neuron numbers and soma size in the PF throughout the lifespan of the R6/2 mouse model using unbiased stereology. Application of the nucleator probe demonstrated that soma size of PF neurons was reduced in R6/2 mice compared to WT at 9 and 13 weeks (wks) (Fig. 1a, w (43) $=0.954, p=0.086, \mathrm{~F}$ (GenotypeXTime $)_{4,33}=1.45, p=0.24, \mathrm{~F}(\text { Time })_{4,33}=3.85, p=0.01$, $\mathrm{F}$ (Genotype $)_{1,33}=8.46, p=0.006$, post hoc comparison: 9 wks $p=0.03$ and 13 wks $p=0.01$ ). Analysis using the optical fractionator probe revealed a significant $29 \%$ decrease in the number of PF neurons in R6/2 mice at 11 wks compared to WT (Fig. 1b, w (43) $=0.972, p=0.37$, F(GenotypeXTime $)_{4,33}=7.65, p=0.00018$, post hoc: 11 wks $p=$ $0.00014 ; 13$ wks $p=0.00015)$. Neuronal degeneration progressed at later timepotins, and by 13 wks the Cavalieri volume estimate of the PF was $31 \%$ smaller in R6/2 mice compared to WT at 13 wks (Fig. 1c-e, w $(43)=.948, p=$ $0.05, \mathrm{~F}(\text { GenotypeXTime })_{4,33}=3.34, p=0.021$; post hoc $p=0.0007$ ). In summary, the main source of TS projections, the PF, shows an early reduction in neuronal size in R6/2 mice at 9 wks, followed by progressive neuronal loss at 11 and 13 wks of age.

\section{The effect of PF lesions on motor behavior in $\mathrm{R} 6 / 2$ and WT mice}

The open field test assesses spontaneous voluntary locomotor activity [39]. To determine the effect of PF lesions on locomotor activity, R6/2 and WT mice were placed in an open field for one hour at 4, 6, 9 and 11 wks. In keeping 

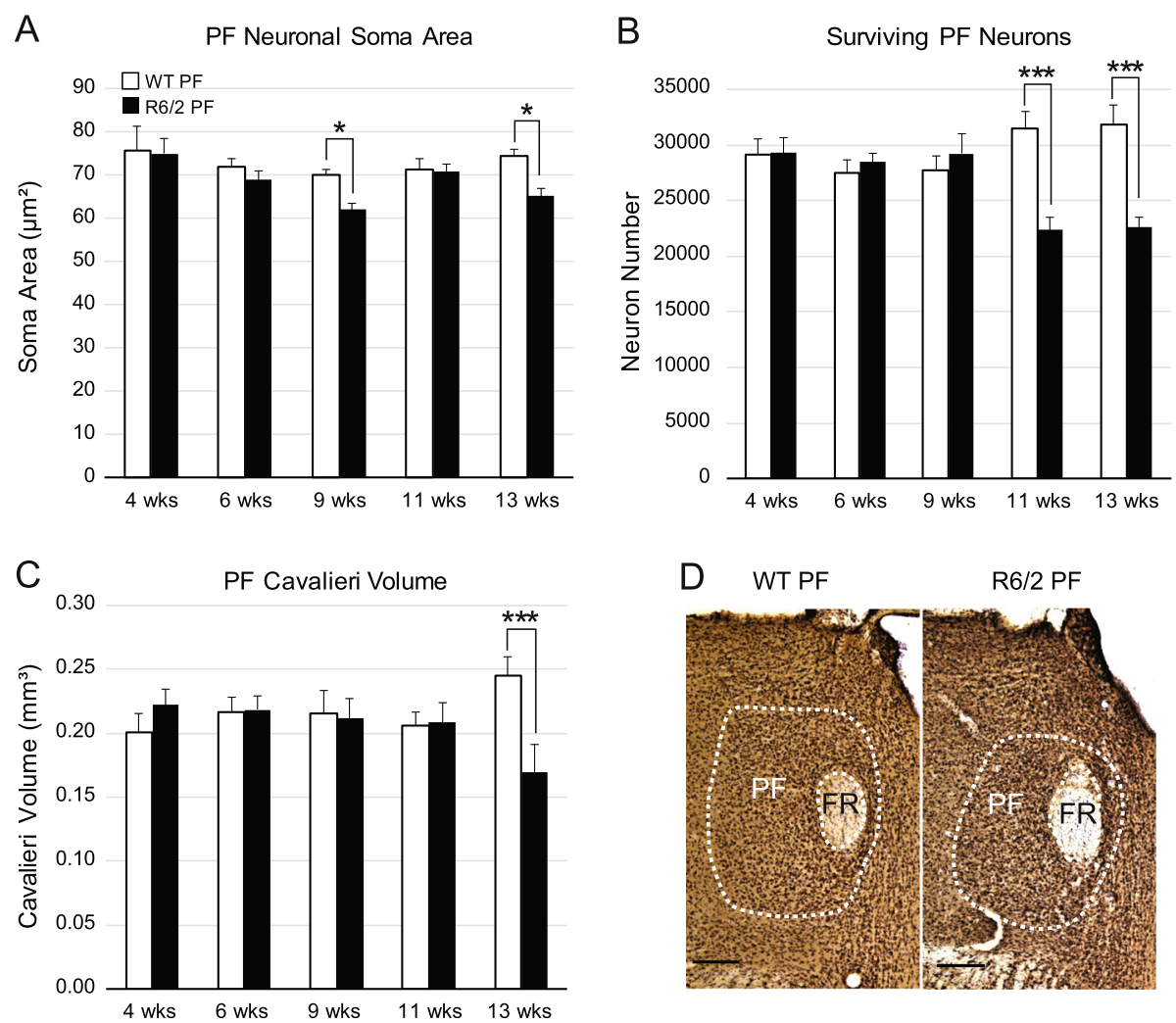

Fig. 1 Morphology of the PF nucleus over the R6/2 mouse lifespan compared to WT controls. (a) There is a significant decrease in neuronal area at $9(p=0.03)$ and 13 wks $(p=0.01)$ in R6/2 compared to WT mice, based on analysis with the nucleator, an unbiased stereology probe. (b) Loss of PF neurons in R6/2 compared to WT mice at 11 wks $(p=0.0001)$ and 13 wks $(p=0.0002)$ determined using the optical fractionator, an unbiased stereology probe. (c) Reduction in PF volume is noted at 13 wks compared to WT mice determined using the Cavalieri probe ( $p=$ 0.0007). (d) Photomicrographs of NeuN/Nissl stained coronal sections outlining the PF nucleus in WT and R6/2 mice at 13 wks. Scale bar: $250 \mu$ m. The data sets were analyzed using a two-way between subject ANOVA and a Tukey HSD post hoc test: * $p<0.05$, *** $p<0.001$. For all panels of Fig. 1, 4 week: WT $(n=3), \operatorname{R6} / 2(n=4) ; 6$ week: WT $(n=4), \operatorname{R6} / 2(n=5) ; 9$ week: WT $(n=4), \operatorname{R6} / 2(n=4)$, 11 week: WT $(n=6), \operatorname{R6} / 2(n=4) ; 13$ week: WT $(n=5)$, R6/2 $(n=4)$. Abbreviations: FR = Fasciculus Retroflexus, PF = Parafascicular Nucleus

with previous studies [34], we found a progressive increase in inactivity time over the R6/2 mouse lifespan starting at 6 wks in both sham-lesioned and lesioned groups compared to their respective WT groups (Fig. 2a, f (TimeXGenotypeXLesion) $)_{3201}=2.82, p=0.04$, post hoc all $p<0.02$ for sham R6/2 mice vs. WT sham as of the 6-week timepoint). Lesioned $\mathrm{R} 6 / 2$ mice spent significantly less time resting at 6 wks compared to sham R6/2 mice $(p=0.01)$, but not at later time-points. Periods of fast movement time reflected inactivity time, with progressive decrease in locomotion in R6/2 compared to WT mice. There was a nonsignificant $(p=0.07)$ trend to increased locomotion at 6 wks in lesioned compared to sham-lesioned R6/2 mice (Fig. 2b, $\mathrm{f}$ (TimeXGenotypeXLesion) $\left.)_{3201}=4.64, p=0.004\right)$. Thus, PF lesioned R6/2 mice progress to the same hypokinetic state with poverty of spontaneous voluntary movement as sham-lesioned counterparts.

The cylinder test assesses exploratory vertical paw reaching limb asymmetry, a complex voluntary behaviour requiring spatial sensorimotor coordination [45].
The number of paw touches on the walls of a cylinder were quantified during a five-minute session in PF lesioned and sham-lesioned WT and R6/2 mice at 4, 6, 9 and 11 wks. A significant reduction in the percent of contralateral limb touches occurs at all post-operative ages after PF lesions in both WT and R6/2 mice compared to sham counterparts (Fig. 2c, f (TimeXGenotypeXlesion $)_{3167}=0.43, \quad p=0.73, \quad \mathrm{~F}(\text { TimeXLesion })_{3167}=$ 13.4, $p<0.00001 ; \quad \mathrm{F}(\text { TimeXGenotype })_{3167}=4.82, \quad p=$ 0.003 , post hoc all $p<0.001$ ). Thus, both $\mathrm{R} 6 / 2$ and WT mice preferentially explored vertical cylinder space with the ipsilateral limb following PF lesions.

The tail suspension test or clasping test is a widely used method for eliciting dystonic movements in HD and dystonia mouse models [34, 46, 47]. To determine if $\mathrm{PF}$ lesions affect the clasping phenotype, mice were tested prior to lesions and at three post-operative timepoints. R6/2 mice had a worsening in dystonic clasping behaviour with aging in both sham and lesion groups with a significant increase in limb clasping in R6/2 mice 

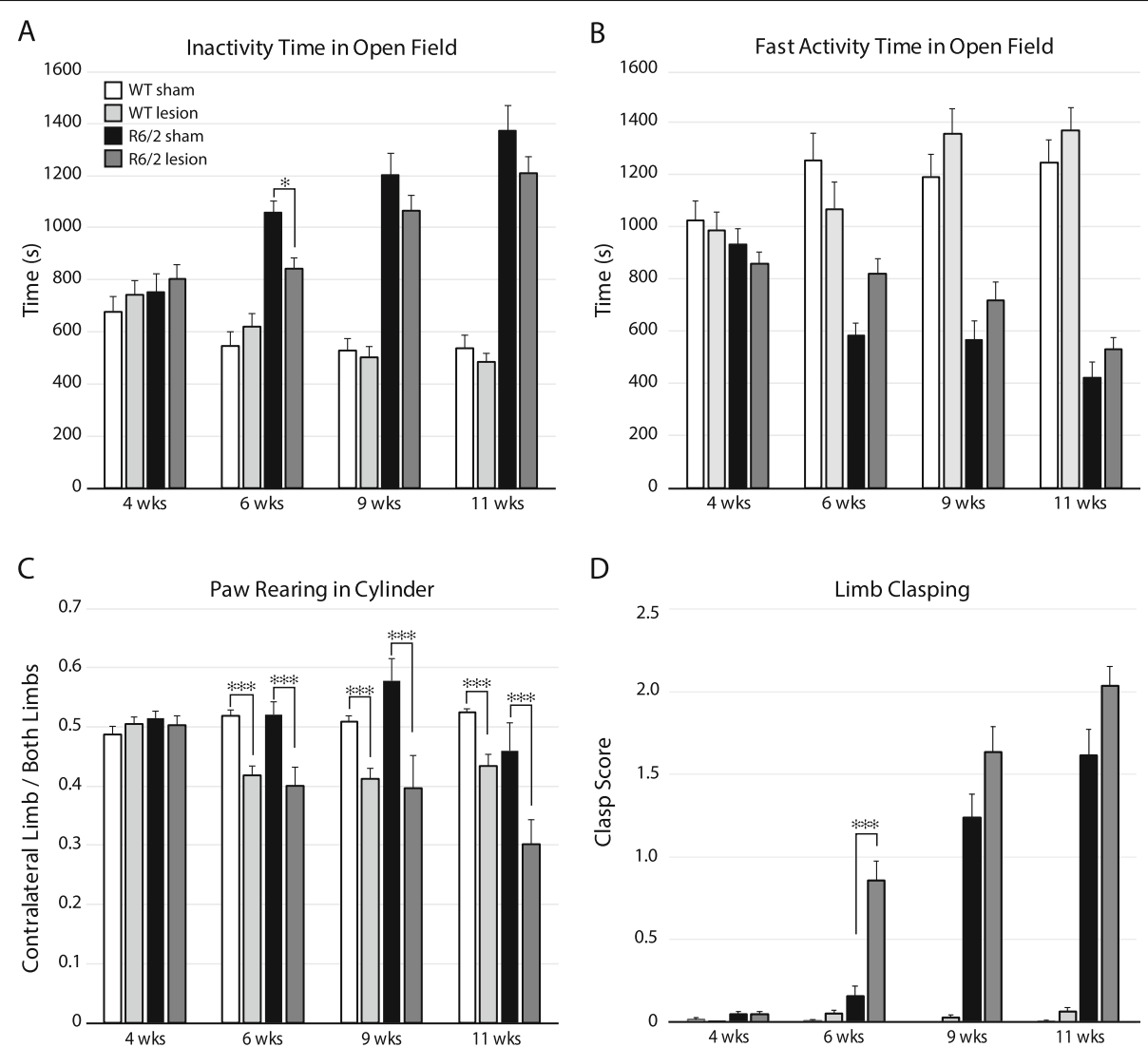

Fig. 2 Characterization of motor behavior following unilateral PF lesions in R6/2 and WT mice. Time spent at rest (a) or moving rapidly (b) during a one-hour open field session demonstrating a transient decrease in rest time at 6 wks in R6/2 mice following PF lesions compared to shamlesions $(p=0.01$ ), that is not sustained at later time-points. (c) The cylinder test assessing voluntary paw reaching motor behaviour shows a persistent decrease in contralateral limb use in both WT and R6/2 mice after PF lesions ( 6 wks $p=0.00004,9$ wks $p=0.00004,11$ wks $p=0.00008$ ). (d) A significant increase in dystonic clasping is noted in PF lesioned R6/2 compared to sham treated R6/2 mice at 6 wks $(p=0.00008)$. A 3-way non-parametric ANOVA was applied to each data set, followed by a Bonferroni post hoc correction; ${ }^{*} p<0.05,{ }^{* *} p<0.001$. For Fig. 2 a-d: WT sham: $n=18$, WT lesion: $n=17$, R6/2 sham: $n=15$, R6/2 lesion: $n=22$

at 6 wks following PF lesions compared to shamlesioned R6/2 mice (Fig. 2d, f (TimeXGenotypeXLesion) $)_{3210}=26.63, p<0.00001$, post hoc: 6 -week $\mathrm{R} 6 / 2$ sham vs 6 -week $\mathrm{R} 6 / 2$ lesion $p=0.00008$ ). Virtually none of the WT mice exhibited clasping and PF lesions did not induce dystonic behaviour in this group. Thus, PF lesions significantly worsen the clasping phenotype in R6/2 mice.

\section{Striatal morphology after early PF lesions}

Previous work in R6/2 mice using unbiased stereology on Nissl stained sections demonstrates that significant striatal cell loss and atrophy occurs at 11 and 13 wks [34]. To determine if the PF has a trophic role for striatal neurons faced with degenerative stress in HD, we quantified the number and soma size of striatal neurons at 11 and 13 wks following PF lesions at 4 wks of age. Since the posterior intralaminar nuclei preferentially afferent the matrix compartment of the striatal mosaic [25-27], neurons of the striosome and matrix compartments were analyzed separately using $\mu$-opiate receptor (MOR) as a marker of striosomes.

The number of matrix neurons in R6/2 mice undergoes a significant and progressive reduction over time compared to WT mice, and there is no effect of PF lesions (Fig. 3b, $\mathrm{w}(23)=0.967, p=0.72, \mathrm{~F}(\text { GenotypeXLesion })_{2,17}=$ $0.49, p=0.62, \mathrm{~F}(\text { Lesion })_{1,17}=0.27, p=0.61, \quad \mathrm{~F}$ (Genotype $)_{2,17}=23.45, p=0.00001$. post hoc: WT vs 11 wks R6/ $2, p=0.03$, WT vs 13 wks R6/2, $p=0.0002,11$ wks $\mathrm{R} 6 / 2$ vs 13 wks $\mathrm{R} 6 / 2, p=0.003$ ). As with neuronal counts, there is a significant reduction in the soma area in R6/2 mice at 11 and 13 wks compared to WT, with no effect of PF lesions (Additional file 1: Figure $\mathrm{S} 1, \mathrm{~W}(23)=0.981, p=0.90$, $\mathrm{F}(\text { GenotypeXLesion })_{2,17}=2.82, p=0.09, \mathrm{~F}(\text { Genotype })_{2,17}=$ 48.78, $p<0.00001$, $\mathrm{F}(\text { Lesion })_{1,17}=1.13, p=0.30$ ).

The number of neurons in striosomes is significantly reduced in R6/2 mice compared to WT at 13 wks, but not at 11 wks. PF lesions did not alter striosome neuron number in any group (Additional file 1: Figure S2, W(23) = $0.986, p=0.63 \mathrm{~F}(\text { GenotypeXLesion })_{2,17}=0.31, p=0.74$, 


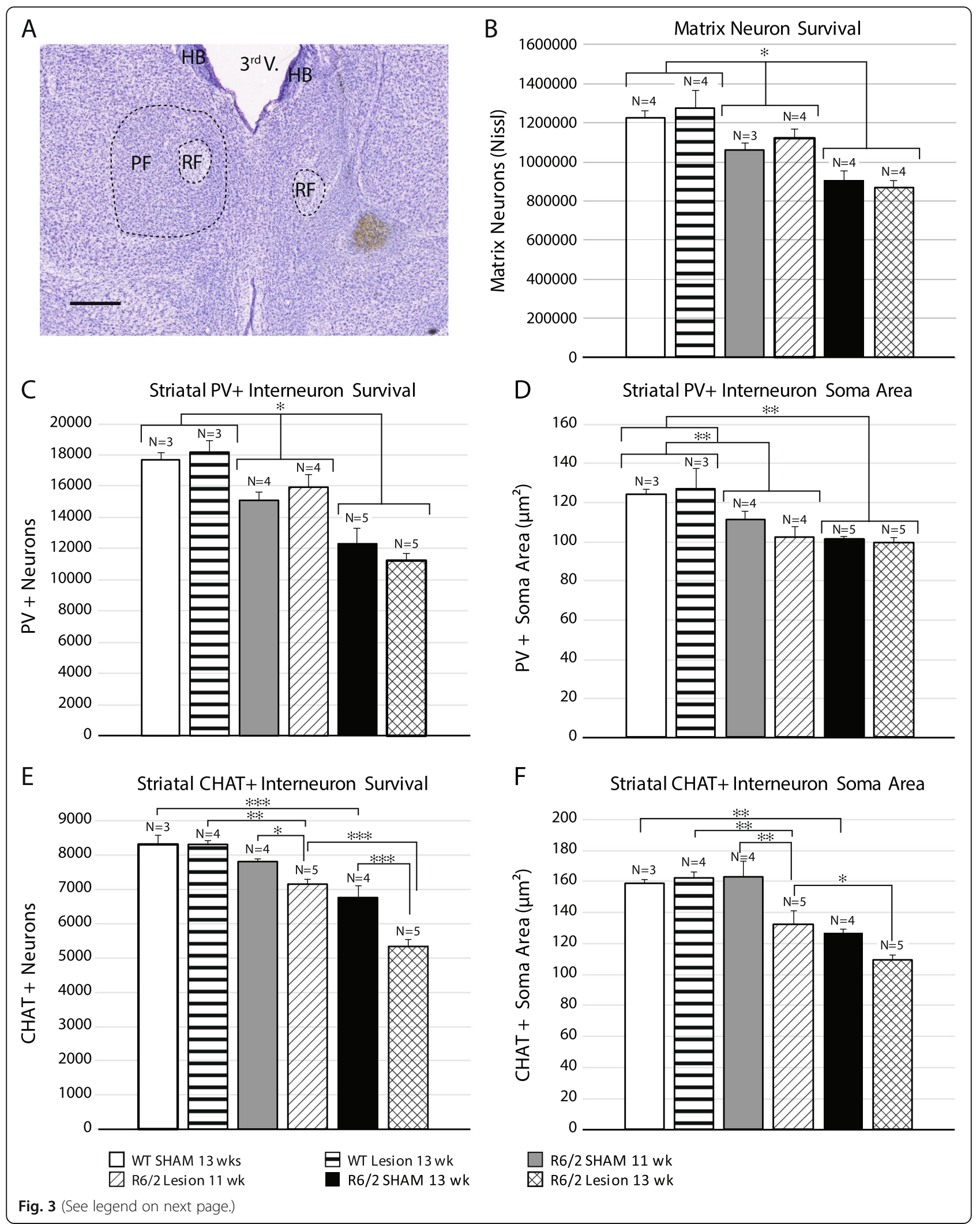


(See figure on previous page.)

Fig. 3 Analysis of number and size of striatal neuron subtypes after PF lesions. These subtypes are known to receive PF input. (a) A typical PF lesion in an R6/2 mouse (scale bar: $0.5 \mathrm{~mm}$ ). (b) Unbiased stereology using the optical fractionator reveals loss of matrix neurons in R6/2 mice at 11 wks with further loss at 13 wks. PF lesions do not alter neuron number in the striatal matrix compartmentin either WT or R6/2 mice. (c, d) Unbiased stereology analysis of striatal PV+ interneurons using the optical fractionator (c) or the nucleator (d) reveals progressive cell loss and atrophy in R6/2 vs. WT mice, with no effect of PF lesions. (e, f) Optical fractionator cell counts (e) and nucleator-derived soma area (f) of ChAT + interneurons show earlier, more severe and progressive cell loss and atrophy in PF lesioned R6/2 mice compared to sham-lesioned R6/2 mice at both 11 wks and 13 wks. Morphology of ChAT + interneurons is not altered by PF lesions in WT mice. Scale bar: $250 \mu \mathrm{m}$. A 2-way between subject ANOVA was applied to each data set followed by a Tukey HSD post hoc test; ${ }^{*} p<0.05,{ }^{* *} p<0.01$, ${ }^{* * *} p<0.001$. Abbreviations: PF $=$ Parafascicular, FR= Fasciculus Retroflexus, 3rd V. = 3rd Ventricle, HB = Habenula

$\mathrm{F}(\text { Lesion })_{1,17}=1.00, p=0.33, \mathrm{~F}(\text { Genotype })_{2,17}=10.65, p=$ 0.001). Striosomal soma area was significantly decreased in 11 and 13 week old R6/2 mice compared to WT but there was no significant effect of PF lesions (Additional file 1: Figure S3, $\mathrm{W}(23)=0.963, p=0.5362, \mathrm{~F}($ GenotypeXLesion $)_{2,17}=0.69, p=0.51, \mathrm{~F}(\text { Genotype })_{2,17}=43.06, p<$ $\left.0.00001, \mathrm{~F}(\text { Lesion })_{1,17}=4.97, p=0.04\right)$. In summary, striatal neuronal loss occurs in R6/2 mice with onset in the matrix compartment, followed by loss in both compartments at late time-points. However, striatal projection neuron loss is not altered in either compartment by early PF lesions.

To determine if TS afferents sustain PV striatal interneurons in the face of degenerative stress [48], neurons were quantified by unbiased stereology in R6/2 mice at 11 and 13 wks following PF lesions at 4 wks. There is a significant and progressive reduction in the number of $\mathrm{PV}+$ neurons in both PF lesioned and sham-lesioned R6/2 mice at 11 and 13 wks compared to WT. However, PF lesions did not alter PV+ interneuron number (Fig. 3c, w $(24)=$ $0.965, p=0.56, \mathrm{~F}$ (GenotypeXLesion $)_{2,18}=0.97, p=0.40$, $\mathrm{F}(\text { Lesion })_{1,18}=0.017, p=0.90, \mathrm{~F}$ (Genotype $)_{2,18}=34.36$, $\mathrm{p}<0.00001$, post hoc: WT vs 11 wks R6/2, $p=0.02$; WT vs 13 wks $\mathrm{R} 6 / 2, p=0.0002$; 11 wks $\mathrm{R} 6 / 2$ vs 13 wks $\mathrm{R} 6 / 2$, $p=0.0003)$. Furthermore, PV+ soma area was reduced with age in R6/2 mice, without an additional effect of PF lesions (Fig. 3d, w (24) $=0.978, p=0.86$, F(GenotypeXLesion $)_{2,18}=0.86, p=0.44 ; \mathrm{F}(\text { Lesion })_{1,18}=0.42, p=0.53$, $\mathrm{F}$ (Genotype $)_{2,18}=16.72, p=0.00008$, post hoc: WT vs 11 week $p=0.003$; WT vs 13 week $\mathrm{R} 6 / 2 \mathrm{p}=0.0002$ ). Thus, $\mathrm{PV}+$ cells undergo progressive atrophy and cell loss in R6/ 2 mice at late stages, but this degeneration is not affected by TS deafferentation.

The TS is the predominant source of glutamatergic input to striatal cholinergic interneurons [30, 49-52] and modulates their physiology [53]. To determine if loss of trophic support from the TS system alters striatal cholinergic neuron survival in R6/2 mice, we quantified choline acetyltransferase $(\mathrm{ChAT})+$ cell number and soma size at 11 and 13 wks following PF lesions at 4 wks. Compared to WT mice, sham-lesioned R6/2 mice show a relative resistance to cholinergic neuron loss compared to MSNs or PV+ interneurons, with detectable reduction in numbers occurring at 13 wks, but not at 11 wks (Fig. 3e, w (25) $=0.982, p=$
0.92, $\mathrm{F}$ (GenotypeXLesion $)_{2,19}=5.81, p=0.01$, post hoc: WT sham vs 13 wks $\mathrm{R} 6 / 2$ sham $p=0.0005 ; 11$ wks $\mathrm{R} 6 / 2$ sham vs 13 wks $\mathrm{R} 6 / 2$ sham $p=0.005)$. PF lesioned R6/2 mice show accelerated loss of cholinergic neurons by 11 wks compared to both PF lesioned WT mice and sham-treated R6/2 mice, with further neuronal loss noted in PF lesioned R6/2 mice at 13 wks (Fig. 3e, post hoc: WT lesion vs 11 week R6/2 lesion, $p=0.002$; WT lesion vs 13 wks R6/2 lesion, $p=0.0001$; 11 wks R6/2 lesion vs 13 wks R6/2 lesion, $p=0.0002 ; 11$ week $\mathrm{R} 6 / 2$ lesion vs 11 wks $\mathrm{R} 6 / 2$ sham $p=$ $0.03,13$ wks R6/2 lesion vs 13 wks $R 6 / 2$ sham, $\mathrm{p}=0.0002$ ). PF lesions did not induce cholinergic cell loss in WT mice. Thus, cholinergic degeneration occurs at a very late timepoint in sham R6/2 mice (13 wks) while PF lesioned R6/2 mice show an accelerated cholinergic cell loss at 11 wks that progresses at 13 wks.

Cholinergic soma area is also reduced at 13 wks in R6/2 compared to WT mice. PF lesions in R6/2 mice are associated with a further decrease in soma area beginning at 11 wks, which progresses by 13 wks (Fig. 3f, w $(25)=0.98$, $p=0.90, \quad \mathrm{~F}$ (GenotypeXLesion) $)_{2,19}=3.36, \quad p=0.05$, post hoc: WT sham vs 13 wks R6/2 sham $p=0.003 ; 11$ wks R6/ 2 sham vs 13 wks $\mathrm{R} 6 / 2$ sham $p=0.02$; WT lesion vs 11 wks R6/2 lesion, $p=0.009$; WT lesion vs 13 wks R6/2 lesion $p=0.0002$; 11 wks R6/2 lesion vs 13 wks R6/2 lesion $p=0.04)$. In summary, there is more severe cholinergic neuron atrophy in PF lesioned R6/2 mice compared to sham-lesioned $R 6 / 2$ mice at 11 wks $(p=0.003)$, with further atrophy noted at 13 wks.

\section{Cholinergic interneuron loss following intrastriatal injection of immunotoxin}

To determine if cholinergic neuron loss is associated with changes in motor phenotype, anti-ChAT conjugated saporin toxins were used to selectively ablate striatal cholinergic interneurons. Mice received intrastriatal injections of either anti-ChAT-saporin or Rabbit IgG-saporin (control saporin) at 4 wks of age and were euthanized at 11 wks (Fig. 4). There was a large reduction in the number of cholinergic neurons assessed using unbiased stereology in both R6/2 and WT mice injected with anti-ChAT -saporin (Fig. 5, W(14) $=0.895 p=0.09$, F(GenotypeXSaporin $)_{1,10}=8.08, \mathrm{p}=0.02$; post hoc: anti-ChATsaporin WT vs Rabbit-IgG -saporin WT: $p=0.0003$, 


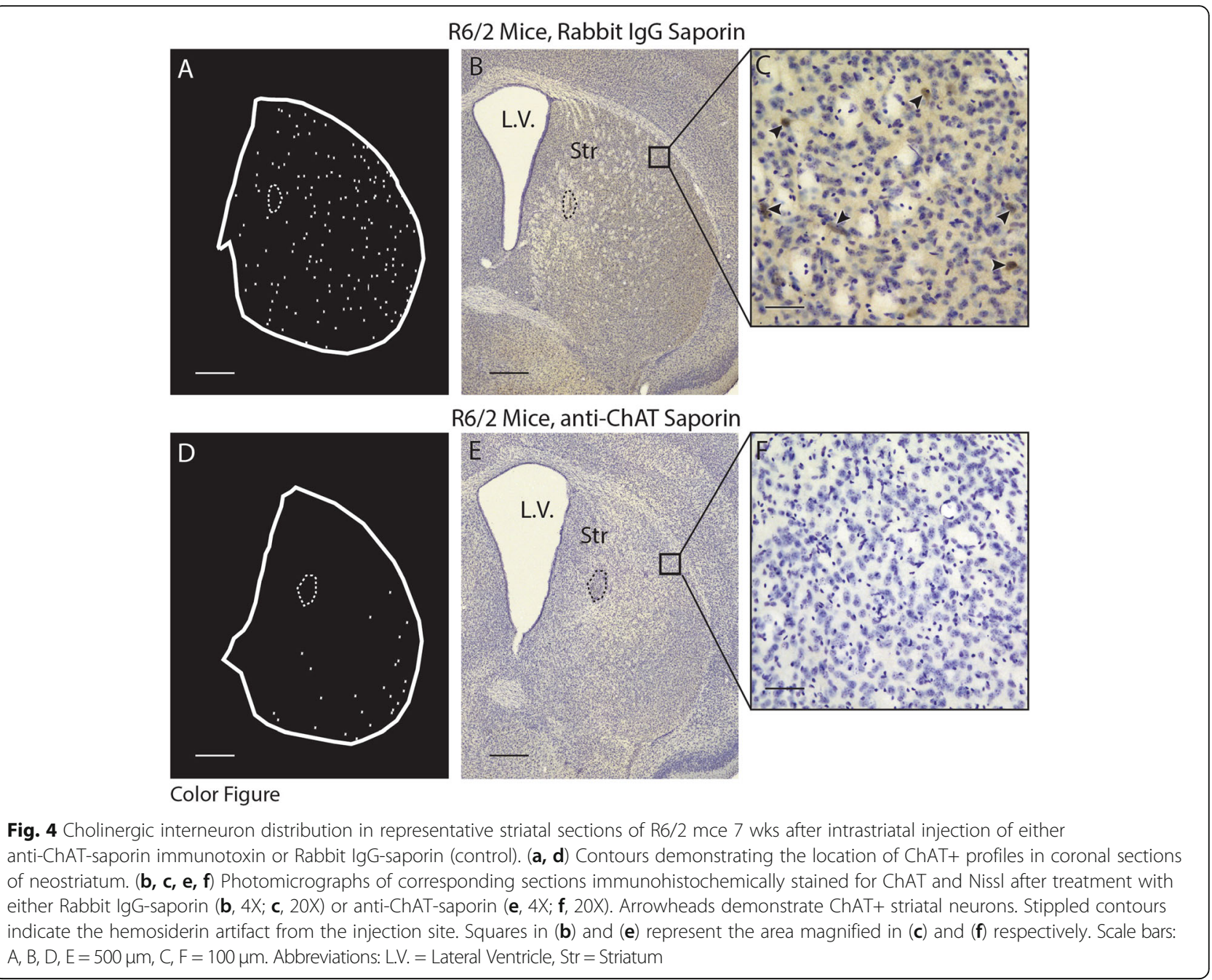

anti-ChAT-saporin R6/2 vs Rabbit IgG-saporin R6/2: $\mathrm{p}=0.0002$ ). The reduction in cholinergic number in anti-ChAT -saporin injected R6/2 mice was greater than in anti-ChAT-saporin injected WT mice $(p=$ 0.004). Soma size of the surviving cells was not different among the four groups (Additional file 1: Figure S4, $\mathrm{W}(14)=0.944 p=0.4754, \mathrm{~F}$ (GenotypeXSaporin $)_{1,10}=$ 0.46, $\quad p=0.51, \quad \mathrm{~F}$ (Genotype $)_{1,10}=3.28, \quad p=0.10$, $\left.\mathrm{F}(\text { Saporin })_{1,10}=0.23, p=0.64\right)$. Thus, an intrastriatal anti-ChAT-saporin injection was effective in eliminating a substantial proportion of striatal cholinergic neurons in both WT and R6/2 mice. Moreover, striatal cholinergic neurons were significantly more vulnerable to the cholinergic immunotoxin in R6/2 compared to WT mice.

\section{The effect of striatal cholinergic ablation on motor behavior in R6/2 and WT mice}

To determine the effect of striatal cholinergic ablation on spontaneous locomotor activity, anti-ChAT-saporin or Rabbit-IgG-saporin injected R6/2 and WT mice were placed in an open field for one hour at 4, 6, 9 and 11 wks. Compared to WT mice, R6/2 mice showed a decrease in spontaneous locomotion as revealed by increased time spent resting in an open field at 6,9 and 11 wks, with no effect of anti-ChAT-saporin injection (Fig. 6a, f (GenotypeXSaporinXTime) $3120=2.50, \quad p=0.06, \quad \mathrm{~F}$ (GenotypeXTime) ${ }_{3120}=13.8, p<0.0001$, post hoc: R6/2 vs WT after 6 wks, all $p<0.005)$. Decreased time spent on fast activity reflected the rest time results (Fig. 6b F(TimeXGenotypeXSaporin) $3120=2.77, p=0.04$; post hoc WT vs $\mathrm{R} 6 / 2$ after 6 weeks all $\mathrm{p}<0.005$, post hoc: all comparisons within genotype for Rabbit-IgG-saporin vs anti-ChATsaporin were not significant). Thus, striatal cholinergic ablation does not affect spontaneous voluntary locomotor behaviour of R6/2 and WT mice.

The cylinder test assessing limb use asymmetry while performing vertical exploration revealed no differences in paw reaching for either of the saporin treated groups (Fig. 6c, w $(60)=0.974, p=0.2354, F$ (GenotypeXSaporinXTime $)_{3142}=0.33, p=0.80, \mathrm{~F}(\text { GenotypeXSaporin })_{1142}=$ 


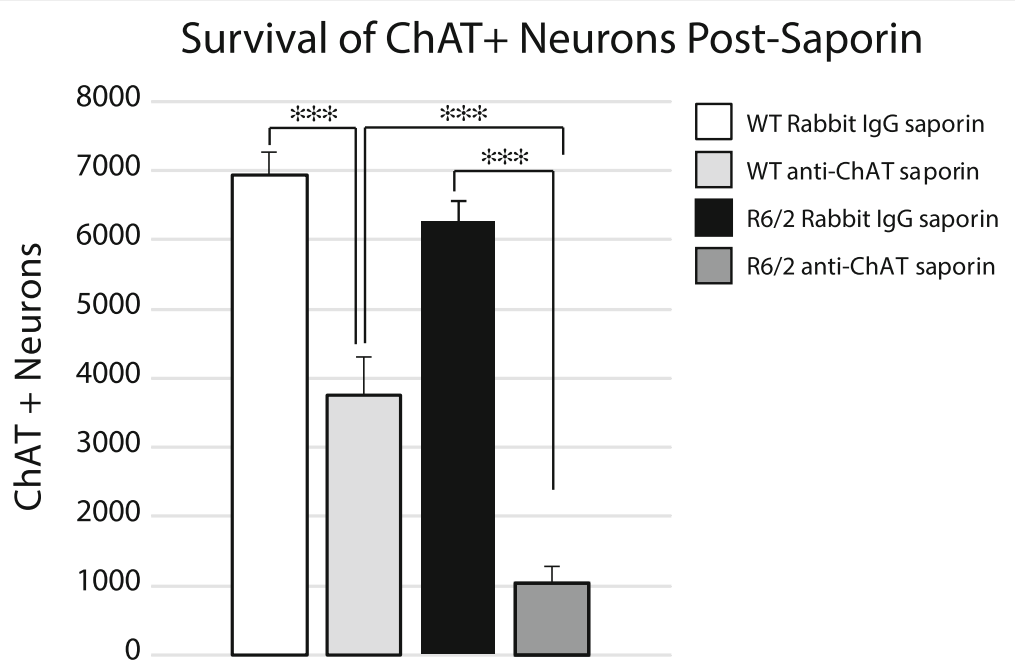

Fig. 5 Unbiased stereological assessment of striatal cholinergic interneuron number 7 wks after intrastriatal injection of anti-ChAT-saporin immunotoxin or Rabbit IgG-saporin (control). ChAT+ neuron numbers were significantly reduced in both R6/2 $(p=0.0002)$ and WT mice $(p=0.0003)$ receiving cholinergic specific toxin compared to control saporin. The reduction in ChAT+ neurons was more pronounced in R6/2 compared to WT mice following exposure to anti-ChAT-saporin $(p=0.0004)$. A two-way between subject ANOVA was applied to the data, followed by a Tukey HSD post hoc test; ${ }^{* *} p<0.001$. WT Rabbit IgG-saporin: $n=3$; WT anti-ChAT-saporin: $n=3$; R6/2 Rabbit IgG-saporin: $n=3$; R6/2 anti-ChAT-saporin: $n=5$

$0.001, \mathrm{p}=0.80, \mathrm{~F}(\text { TimeXSaporin })_{3142}=0.14, \quad p=0.94$, $\left.\mathrm{F}(\text { TimeXGenotype })_{1142}=0.51, p=0.67\right)$. Thus, unilateral striatal cholinergic ablation does not induce a paw preference during voluntary movement in either $\mathrm{R} 6 / 2$ or WT mice.

To determine if cholinergic ablation affected the development of the dystonic phenotype in R6/2 mice, limb clasping was assessed at 4, 6, 9 and 11 weeks. Dystonic clasping behaviour with aging worsened in R6/2 mice in both anti-ChAT-saporin and Rabbit IgG-saporin treated groups. There was a significant increase in clasping at 6 wks in anti-ChAT-saporin treated R6/2 mice compared to control anti-Rabbit IgG-saporin treated R6/2 mice (Fig. 6d, f (TimeXGenotypeXSaporin) $3114=4.31, p=0.006$; post hoc: 6-week anti-chat saporin $\mathrm{R} 6 / 2$ vs 6 -week control anti-Rabbit IgG-saporin R6/2 $p=0.04$ ). Both anti-ChATsaporin and Rabbit-IgG-saporin injected WT mice exhibited virtually no clasping behaviour. Thus, striatal cholinergic ablation significantly accelerates the development of a dystonic phenotype in R6/2 mice.

\section{Discussion}

Dysfunctional striatal afferents may play an important role in mechanisms leading to motor symptoms in HD $[24,31,32,54]$. Here we demonstrate that the major source of thalamostriatal (TS) projections, the CM-PF complex in primates or the PF in rodents, degenerates in the R6/2 mouse model of HD. Furthermore, depriving the R6/2 striatum of TS inputs prior to onset of motor signs results in an acceleration of dystonic involuntary movements. Complex voluntary motor behaviours such as spontaneous paw reaching are also impaired following TS deafferentation in R6/2 compared to WT mice. The time course of worsening of spontaneous locomotion in an open field is not altered after unilateral TS lesions. Morphological analysis of degenerating striatal neurons indicates that the cholinergic interneuron subtype is especially vulnerable to TS denervation in the R6/2 mouse. In contrast, the time course of loss of MSNs and parvalbumin-positive interneurons is unaltered following PF lesions in R6/2 mice. Finally, induction of striatal cholinergic loss in the R6/2 striatum using immunotoxins reproduces the acceleration of dystonia seen after TS denervation in R6/2 mice, suggesting that abnormal TScholinergic interactions are an important contributor to the dystonia phenotype in HD.

\section{The role of afferents in loss of striatal neurons in HD} In HD, mhtt protein is expressed throughout the organism, but the striatum is especially vulnerable to degeneration [2]. Striatal neurons are likely lost due to multiple cell autonomous mechanisms [8, 10-13, 15]. Striatal afferents may contribute to cell non-autonomous mechanisms of neuron dysfunction or death by loss of anterograde neurotrophic support $[16,55,56]$, excitotoxicity related to abnormal ionotropic receptor signaling [12, 57-59] or abnormal synaptic transmission [31, 60].

Glutamatergic afferents from the cerebral cortex to the striatum may participate in neuronal loss in HD by inducing excitotoxicity $[12,57-59]$. Depriving the HD striatum of cortical afferents in the R6/2 model using lesions restricted mainly to the motor cortex appears to protect 


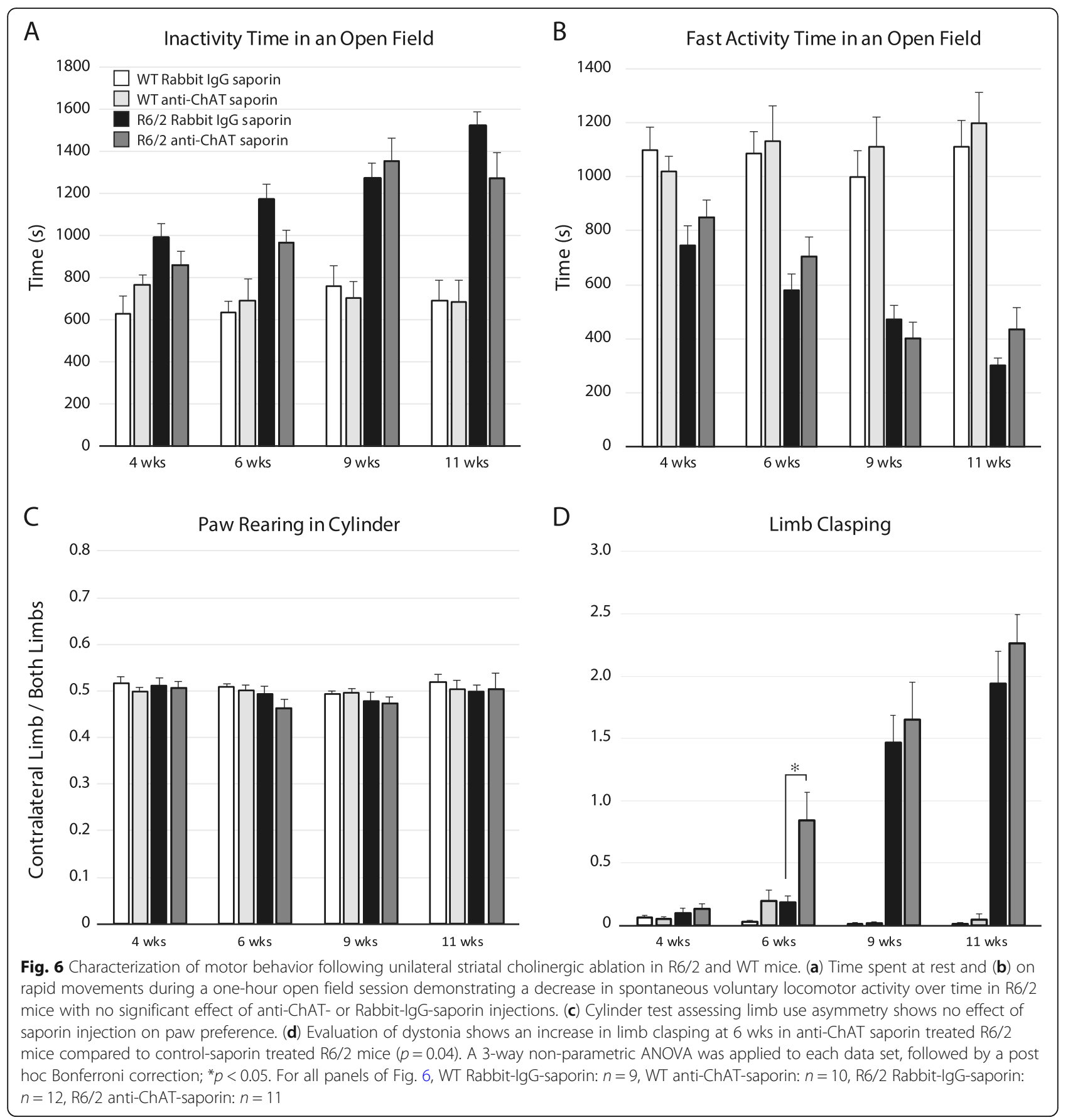

neurons sampled from the dorsolateral striatum from atrophy, although neuronal counts were not available [14]. These lesioned mice also showed reduced clasping [14], a finding that may be confounded by pyramidal effects from lesioning the motor cortex. An excitotoxic role for corticostriatal (CS) glutamatergic afferents on striatal MSNs in HD was suggested. This is in keeping with previous work by several groups indicating that aberrant calcium signaling through extra-synaptic NMDA receptor (NMDAR) stimulation and increased sensitivity of NMDARs is linked to MSN excitotoxicity in HD [9-12, 15, 57-59]. On the other hand, CS afferents are potentially protective for MSNs, an effect that may be mediated by synaptic glutamatergic mechanisms $[61,62]$ or by anterograde neurotrophin-related effects [34, 36, 55, 56, 63].

In comparison to the cerebral cortex, relatively little is known of the role of the other major source of glutamatergic striatal afferents, the posterior intralaminar nuclei, in mechanisms of striatal dysfunction in HD. In vivo imaging of patients demonstrates that thalamic atrophy 
occurs early in the course of HD [23], and autopsy studies provide evidence for significant loss of CM-PF neurons [24]. Ultrastructural evidence from the Q140 heterozygous mouse model of HD provides morphological evidence for early TS dysfunction, since TS synapses on MSNs are lost by one month, whereas loss of corticostriatal synapses is observed relatively late, at one year [32]. Recent work in 9-12 week old R6/2 mice also suggests abnormal morphology of TS inputs [64]. The present work demonstrates that PF neurons, the main source of TS inputs, are lost in R6/2 mice coincident with the onset of detectable neurodegenerative changes in the neostriatum on Nissl stains [34]. Indeed. PF neuron atrophy is already detected $9 \mathrm{wks}$, prior to significant striatal neuronal loss. There is progressive loss of PF neurons at 11 and 13 wks correlating with worsening dystonia and other locomotor deficits. Interestingly, the early significant reduction of average neuronal soma size at 9 wks is followed by apparent normalization of average soma size at 11 wks. Neuronal loss and average cell size do not necessarily correlate. Indeed, as degeneration progresses, it is expected that neurons with decreased cell size will be lost preferentially. As a result, there would be a relative abundance of larger neurons with apparent normalization of cell size. With further progression of degeneration, the remaining neurons that were initially spared may also degenerate resulting in the observed reduction in soma area at 13wks. Alternatively, the degenerating PF neurons may represent a specific subpopulation. For example, different cellular subpopulations within the mouse PF may provide preferential inputs to MSNs or striatal cholinergic interneurons [65]. It would be of interest to determine whether specific intralaminar thalamic subpopulations degenerate in post-mortem HD brains and in HD models.

Another important differentiating factor between glutamatergic striatal afferents is revealed by physiological studies in slice preparations indicating that the PF preferentially elicits NMDA currents in MSNs while CS afferents evoke a higher proportion of AMPA- mediated post-synaptic currents $[26,66]$. The apparently larger contribution of NMDA mediated post-synaptic currents from PF inputs compared to CS afferents [26, 66], may suggest a differential role for the TS or CS in excitotoxicity $[64,67]$. Differential inputs to patch and matrix compartments that comprise the striatal mosaic may provide a clue to differences in thalamic or corticalderived afferent effects on MSN survival in HD. Unlike the cerebral cortex which innervates all MSNs, the PF provides dense afferents almost exclusively to the matrix compartment of the striatum [25-27]. Therefore, potential excitotoxicity from the PF would be expected to have differential effects on MSNs in either compartment. Alternatively, TS afferents may also provide a sustaining role for vulnerable striatal neurons in HD [34], analogous to their trophic survival role in normal striatal development [36]. Indeed, BDNF is enriched in PF neurons $[36,68]$, and there is an early reduction in BDNF mRNA in striatal afferents including in the PF of R6/2 mice [34]. Furthermore, the ability to activate striatal TrkB receptors in the $R 6 / 2$ striatum is impaired [13]. Importantly, the present findings indicate that early TS lesions in R6/2 mice have no significant effect on MSN size or number using unbiased stereology performed separately on either patch or matrix compartments of sham and lesioned R6/2 mice. These findings suggest that loss of projection neurons in HD likely involves a complex interplay between neurotrophic, excitotoxic and cell autonomous mechanisms, and loss of glutamatergic TS afferents is not a major factor determining survival of MSNs in the HD striatum.

\section{Vulnerability of specific interneuron subtypes}

Although striatal interneuron subtypes comprise only 5$10 \%$ of the striatal population, they are important modulators of striatal function in health and disease states [5, 37, 53, 69-76]. Striatal interneurons include cholinergic neurons, and GABAergic subtypes that express somatostatin, parvalbumin, or calretinin [76]. Striatal interneurons modulate MSNs via local synapses, and also at a distance across patch/matrix boundaries [77, 78]. In rodents, the PF contributes only a small proportion of excitatory synapses to striatal PV neurons [29, 74]. In contrast, striatal PV interneurons receive dense asymmetric inputs from the cerebral cortex [74, 79] suggesting they may be more sensitive to pathological changes affecting the cortex rather then the PF in HD. Early work suggested that striatal PV interneurons may be spared in HD, [80] but more recent findings in autopsied HD brains indicate an important reduction in PV interneurons [5]. The present results provide stereological evidence for a decrease in soma size and number of striatal PV interneurons in the R6/2 model of HD. Early PF lesions in the R6/2 model do not accelerate the time course of degeneration of $\mathrm{PV}$ interneurons. As with MSNs, degeneration of PV neurons is likely due to a combination of cell autonomous and non-autonomous mechanisms [48, 81], but the TS projection does not play a major survival role for PV interneurons in the face of neurodegenerative stress in HD.

Cholinergic interneurons make up $1 \%$ of all striatal neurons, synapse on most MSNs and other interneurons, and modulate dopaminergicand glutamatergic terminals in the striatum [72]. Ultrastructural studies indicate that the predominant glutamatergic input to cholinergic interneurons is from the posterior intralaminar nuclei in rodents and monkeys [30, 49-52]. Although physiological and viral-based tracing studies [82, 83] suggest that cholinergic interneurons may receive cortical input, there is little ultrastructural evidence for 
inputs from the cerebral cortex in rodents [28]. Classically, cholinergic interneurons were thought to be spared in HD [4]. However, recent evidence points to significant striatal cholinergic dysfunction in HD patients, including reduced synthetic and vesicular proteins [84, 85], and decreased ChAT+ cell numbers [6]. Several electrophysiological studies have shown abnormal cholinergic responses to afferent stimulation and decreased acetylcholine release in slice preparations in R6/2 or Q175 mouse models [54, 86-88]. In the R6/1 mouse model of HD, striatal vesicular acetylcholine transporter, and ChAT mRNA and protein concentrations are reduced in tissue lysates, and $m h t t$ aggregates accumulate in cholinergic neurons [84]. Ultrastructural evidence in the Q140 mouse model of HD indicates that striatal cholinergic interneurons have a decreased number of TS synapses, reduced cell diameter and fewer dendritic branches [31]. In keeping with this work, ex vivo brain slices derived from the Q175 mouse model of HD show decreased synaptic facilitation at cholinergic targets in response to PF stimulation [54]. The present results from R6/2 mice suggest that neuronal degeneration in the PF occurs early in the course of $\mathrm{HD}$, and therefore contributes to loss of TS synaptic integrity and function [64]. The observed loss of PF neurons precedes cholinergic neuron atrophy and cell loss which normally only occurs at late timepoints suggesting a relative resistance of cholinergic neurons to degeneration in HD. Early PF lesions accelerate the atrophy and loss of cholinergic neurons in R6/2 mice, suggesting that these neurons are especially dependent on sustaining thalamic input in the face of $m h t t$ related neurodegenerative stress.

Multiple mechanisms may underlie the differential vulnerability of striatal cholinergic interneurons to TS deafferentation compared to other striatal populations. The fact that the glutamatergic TS system provides more prominent input to cholinergic interneurons [30, 49, 50, 52] compared to PV interneurons $[29,74]$ may explain their sensitivity to TS deafferentation in R6/2 mice through both glutamatergic and trophic factor receptor dependent mechanisms. For example, cholinergic interneurons express lower levels of ionotropic NMDA-2A and metabotropic GluR1/5 glutamate receptors [89] then other striatal cell types, but maintain high NMDA-2B expression [90-92]. Signaling from mGLUR5 and synaptic NMDA receptors enriched in NMDA-2A subunits can stabilize mitochondrial membranes and promote cell survival, $[61,62]$ while neurotoxic extrasynaptic NMDA receptors rich in NMDA-2B subunits contribute to mitochondrial failure and cell death in MSNs in various HD models [9, 11, 15, 57, 59-61]. In keeping with this evidence, the present in vivo results demonstrate striatal cholinergic interneurons in R6/2 mice are more susceptible to a mitochondrial toxin than WT neurons suggesting that they are more vulnerable to cellular energy failure.

In addition to glutamatergic modulation of cell death, neurotrophins may also play an important role in cholinergic neuron vulnerability to TS loss in HD. The neurotrophin brain-derived neurotrophic factor (BDNF) promotes forebrain cholinergic neuron maintenance, growth [93], and survival [94, 95]. In particular, ChAT+ striatal neurons express both TrkA and TrkB receptors $[96,97]$ and contain BDNF protein [98]. Given that the striatum lacks BDNF mRNA [68, 99-103], the BDNF protein in ChAT+ cells may derive from post-synaptic internalization and endosomal trafficking of BDNF released from afferents [104-110]. Endosomal trafficking of TrkB/BDNF complexes towards the soma provides trophic support to neurons, is regulated by $h t t$ and is reduced in the presence of $m h t t$ [108, 111114]. Since a higher proportion of cholinergic neurons express $h t t$ compared to other striatal subpopulations [98, 115], they may be especially vulnerable to loss of BDNF. Importantly, the TS system is the main source of glutamatergic afferents to cholinergic neurons [30, 49-52] is enriched in BDNF mRNA [34, 68], and PF lesions reduce striatal BDNF-TrkB signaling in neonatal rodents [36]. The PF may therefore contribute to the relative resistance to degeneration of cholinergic neurons. Loss of BDNF following PF lesions or degeneration in HD may make cholinergic neurons more vulnerable to degeneration in HD.

\section{Implications of thalamostriatal and cholinergic dysfunction for dystonia and HD}

Dystonia can be a motor feature of both hypokinetic and hyperkinetic disorders including primary and secondary dystonic syndromes, and other neurodegenerative diseases [1116-118]. Secondary dystonia can occur following lesions in different parts of the thalamic, cerebellar or basal ganglia network [119-124]. Dystonia is also a common symptom in HD, and worsens with disease progression, but appears not to correlate with chorea or bradykinesia [1]. Clasping behaviour is considered a surrogate for dystonia in rodent models as it mimics the sustained muscle contractions and abnormal postures seen in humans [116]. Clasping behaviour occurs in many animal models of $\mathrm{HD}$ and primary dystonia [34, $47,71,125]$. Furthermore, clasping behavior is well studied in the R6/2 mouse and worsens significantly as the model progresses [34], similar to the age related increase in dystonia seen in HD patients [1].

Basal ganglia, cerebellar, brainstem and cortical dysfunction are proposed in both human dystonia and in the many animal models exhibiting clasping behaviours reminiscent of dystonia [125, 126]. Interrogation of different components of the striatal micro-circuitry in animal models allows better understanding of dystonia. DYT1 mouse models of primary dystonia show decreased 
intrastriatal dopamine release possibly due to reduced nicotinic cholinergic tone [127], and paradoxical dopamine D2 receptor mediated excitation of cholinergic neurons $[128,129]$. These altered cholinergic-dopaminergic interactions in DYT1 mice impair long-term depression in MSNs and increase corticostriatal synaptic long-term potentiation, leading to abnormal striatal output [126, 127, $129,130]$. These synaptic deficits may even occur early in brain development, as mice with selective forebrain DYT1 knockout show an early clasping phenotype associated with post-natal loss of cholinergic striatal interneurons and decreased striatal acetylcholine release [47]. Similar changes in striatal cholinergic micro-circuitry are described in HD models. These include: the inability of striatal cholinergic cells to undergo long-term potentiation with an associated inability of MSNs to undergo long-term synaptic depression [87], decreased acetylcholine release [86, 88], and increased MSN and cholinergic responses to cortical excitation [54, 64]. These abnormalities are compounded in HD by atrophy and loss of striatal cells $[2,5-7]$.

The posterior intralaminar nuclei are important drivers of cholinergic activity in the normal striatum [37, 53, 69, 70, 73, 75, 131, 132]. Cholinergic neurons modulate longterm plasticity of MSNs by regulating dopamine and glutamate co-release onto MSNs through pre-synaptic acetylcholine receptors on glutamatergic and dopaminergic terminals [132]. More specifically, the pause-response of cholinergic neurons to TS stimulation, which is mediated by D2-receptors on cholinergic cells as well as presynaptic nicotinic receptors on dopaminergic terminals, helps to transiently inhibit both direct and indirect pathway MSNs responses to cortical stimulation and then later facilitate post-synaptic cortical glutamatergic excitation of indirect pathway neurons, thereby preferentially driving the network towards action cessation [53]. Loss of the PF-cholinergic mediated tuning of striatal projection neurons leads to an imbalance between competing basal ganglia pathways and is thought to impair saliency estimation and motor program selection [69, 70, 73, 131, 133], and contribute to the generation of dystonia [126]. Indeed, TS-cholinergic deficits have been shown in HD and dystonia models. For example, in a DYT1 mutant mouse, the normal pause-response is replaced by erratic firing of cholinergic cells to TS stimulation [130] and in the Q175 HD mouse, there is reduced TS synaptic facilitation of cholinergic interneurons and loss of the normal pause-spike response to TS stimulation [54]. The present work demonstrates that lesioning either the TS system or striatal cholinergic interneurons exacerbates dystonia in the R6/2 HD mouse. Altogether these findings suggest that dysfunction of both the TS system and loss of cholinergic interneurons plays an important role in the generation of dystonia in HD and in primary dystonia models.

In addition to the striatum and the TS system, the cerebellum is proposed as an important part of the dystonia network. Evidence from imaging studies suggests reduced cerebellar activity, degeneration of the cerebellothalamocortical pathway and abnormal cerebellar sensorimotor integration in dystonia patients [134-136]. HD patients show cerebellar degeneration that correlates with a worse motor score [2, 137, 138]. Furthermore, models which have a severe clasping phenotype such as R6/2 and Hdh100 HD mice also demonstrate a loss of Purkinje cells at late timepoints $[139,140]$.

The intralaminar nuclei receive afferents from deep cerebellar nuclei and form a disynaptic link between the basal ganglia and the cerebellar nuclei [141-143]. The output of the cerebello-thalamic circuit plays an important role in saliency estimation and action selection [69, $70,73,131]$. Similar to the effect of unilateral cerebellar lesions in rats [144], PF lesions in the present work led to decreased spontaneous contralateral paw use in both WT and R6/2 mice when exploring a cylinder. This provides evidence for a role for the TS system in evaluation of salient sensory information and appropriate motor program selection. Furthermore, both thalamic and cerebellar strokes lead to secondary dystonia in susceptible individuals [119-124]. Atrophy and cell loss in the TS system and the cerebellum [2, 24, 137] may therefore contribute to the dystonia network in HD. TS afferents degenerate in R6/2 mice expressing a dystonic clasping phenotype, and early PF lesions in R6/2 mice lead to a worsening of dystonia. We therefore propose that TS degeneration, with downstream pathology at cholinergic targets, plays an important part in the network leading to expression of dystonia in HD and possibly in other dystonic syndromes.

\section{Conclusion}

Thalamostriatal afferents provide important trophic support to striatal cholinergic neurons in Huntington's disease. Furthermore, pathological dysfunction of the TS system and cholinergic interneurons is closely linked to the generation of a dystonic phenotype in HD models. This work provides a new understanding of mechanisms of striatal degeneration and motor symptoms in HD, and may pave the way for development of effective therapies for those affected by this currently incurable neurodegenerative disorder.

\footnotetext{
Abbreviations

3rd V.: 3rd ventricle; AMPA: a-amino-3-hydroxy-5-methyl-4-isoxazolepropionic acid; BDNF: Brain-derived neurotrophic factor; CC: Corpus callosum;

ChAT: Choline acetyltransferase; CM-PF: Centromedian-parafascicular;

FR: Fasciculus retroflexus; HB: Habenula; HD: Huntington's disease; L.V.: Lateral ventricle; mhtt : Mutant huntingtin gene; MSNs : Medium spiny projection neurons; NMDA : N-methyl D-aspartate; NMDAR: NMDA receptor;

PF: Parafascicular; PV: Parvalbumin; Str: Striatum; Trk: Tyrosine kinase receptor; TS: Thalamostriatal; wks: Weeks; WT: Wildtype
} 


\section{Authors' contributions}

GCS designed the project, analyzed and collected the behavioural and morphological data and wrote the manuscript. WR collected the behavioural and genetics data and helped edit the manuscript. RCS analyzed the behavioural and morphological data for the cholinergic immunotoxin experiment. AFS designed the experiment, oversaw the project, acquired funding, and edited the manuscript. All authors read and approved the final manuscript.

\section{Funding}

This work was made possible by grants from the Canadian Institutes of Health Research (CIHR), Natural Sciences and Engineering Research Council of Canada (NSERC), and the Weston Brain Institute.

\section{Availability of data and materials}

The data analysed during the current study are available from the corresponding author on reasonable request.

\section{Ethics approval and consent to participate}

All experiments were approved by the research ethics board at the Montreal Neurological Institute in accordance with the standards and guidelines of the Canadian Council on Animal Care. A consent to participate is not applicable to this study.

\section{Consent for publication}

Not applicable.

\section{Competing interests}

The authors declare that they have no competing interests.

Received: 13 November 2019 Accepted: 3 January 2020

Published online: 07 February 2020

\section{Additional file}

Additional file 1: Experimental Timeline. Figure S1. Matrix Neuron Soma Area in WT and R6/2 mice. Figure S2. Striosome cell count in WT and R6/2 mice. Figure S3. Striosome Neuron Soma Area in WT and R6/2. Figure S4. CHAT+ Cell Soma Area in Saporin Treated Animals

Received: 13 November 2019 Accepted: 3 January 2020

Published online: 07 February 2020

\section{References}

1. Louis ED, Lee P, Quinn L, Marder K (1999) Dystonia in Huntington's disease: prevalence and clinical characteristics. Mov Disord 14:95-101

2. Vonsattel JP, Difiglia M (1998) Huntington disease. J Neuropathol Exp Neurol 57:369-384

3. (1993) A novel gene containing a trinucleotide repeat that is expanded and unstable on Huntington's disease chromosomes. The Huntington's Disease Collaborative Research Group. Cell 72:971-983

4. Ferrante RJ, Beal MF, Kowall NW, Richardson EP Jr, Martin JB (1987) Sparing of acetylcholinesterase-containing striatal neurons in Huntington's disease. Brain Res 411:162-166

5. Reiner A, Shelby E, Wang H, Demarch Z, Deng Y, Guley NH, Hogg V, Roxburgh R, Tippett LJ, Waldvogel HJ, Faull RL (2013) Striatal parvalbuminergic neurons are lost in Huntington's disease: implications for dystonia. Mov Disord 28:1691-1699 https://doi.org/10.1002/mds.25624

6. Massouh M, Wallman MJ, Pourcher E, Parent A (2008) The fate of the large striatal interneurons expressing calretinin in Huntington's disease. Neurosci Res 62:216-224 https://doi.org/10.1016/.neures.2008.08.007

7. Cicchetti F, Parent A (1996) Striatal interneurons in Huntington's disease: selective increase in the density of calretinin-immunoreactive medium-sized neurons. Mov Disord 11:619-626 https://doi.org/10.1002/mds.870110605

8. Crotti A, Benner C, Kerman BE, Gosselin D, Lagier-Tourenne C, Zuccato C, Cattaneo E, Gage FH, Cleveland DW, Glass CK (2014) Mutant Huntingtin promotes autonomous microglia activation via myeloid lineage-determining factors. Nat Neurosci 17:513-521 https://doi.org/10. 1038/nn.3668
9. Dau A, Gladding CM, Sepers MD, Raymond LA (2014) Chronic blockade of extrasynaptic NMDA receptors ameliorates synaptic dysfunction and prodeath signaling in Huntington disease transgenic mice. Neurobiol Dis 62: 533-542 https://doi.org/10.1016/.nbd.2013.11.013

10. Fernandes HB, Baimbridge KG, Church J, Hayden MR, Raymond LA (2007) Mitochondrial sensitivity and altered calcium handling underlie enhanced NMDA-induced apoptosis in YAC128 model of Huntington's disease. J Neurosci 27:13614-13623 https://doi.org/10.1523/JNEUROSCl.3455-07.2007

11. Gladding CM, Sepers MD, Xu J, Zhang LY, Milnerwood AJ, Lombroso PJ, Raymond LA (2012) Calpain and STriatal-enriched protein tyrosine phosphatase (STEP) activation contribute to extrasynaptic NMDA receptor localization in a Huntington's disease mouse model. Hum Mol Genet 21: 3739-3752 https://doi.org/10.1093/hmg/dds154

12. Li L, Fan M, Icton CD, Chen N, Leavitt BR, Hayden MR, Murphy TH, Raymond LA (2003) Role of NR2B-type NMDA receptors in selective neurodegeneration in Huntington disease. Neurobiol Aging 24:1113-1121

13. Nguyen KQ, Rymar W, Sadikot AF (2016) Impaired TrkB signaling underlies reduced BDNF-mediated trophic support of striatal neurons in the R6/2 mouse model of Huntington's disease. Front Cell Neurosci 10:37 https://doi. org/10.3389/fncel.2016.00037

14. Stack EC, Dedeoglu A, Smith KM, Cormier K, Kubilus JK, Bogdanov M, Matson WR, Yang L, Jenkins BG, Luthi-Carter R, Kowall NW, Hersch SM, Beal MF, Ferrante RJ (2007) Neuroprotective effects of synaptic modulation in Huntington's disease R6/2 mice. J Neurosci 27:12908-12915 https://doi.org/ 10.1523/JNEUROSCI.4318-07.2007

15. Zhang H, Li Q, Graham RK, Slow E, Hayden MR, Bezprozvanny I (2008) Full length mutant huntingtin is required for altered $\mathrm{Ca} 2+$ signaling and apoptosis of striatal neurons in the YAC mouse model of Huntington's disease. Neurobiol Dis 31:80-88 https://doi.org/10.1016/j.nbd.2008.03.010

16. Zuccato C, Liber D, Ramos C, Tarditi A, Rigamonti D, Tartari M, Valenza M, Cattaneo E (2005) Progressive loss of BDNF in a mouse model of Huntington's disease and rescue by BDNF delivery. Pharmacol Res 52:133139. https://doi.org/10.1016/.jphrs.2005.01.001

17. Coyle J, Price D, DeLong M (1983) Alzheimer's disease: a disorder of cortical cholinergic innervation. Science 219:1184-1190 https://doi.org/10.1126/ science.6338589

18. Teipel SJ, Cavedo E, Hampel H, Grothe MJ (2018) Basal forebrain volume, but not hippocampal volume, is a predictor of global cognitive decline in patients with Alzheimer's disease treated with cholinesterase inhibitors. Front Neurol 9:642 https://doi.org/10.3389/fneur.2018.00642

19. Braak H, Del Tredici K, Rub U, de Vos RA, Jansen Steur EN, Braak E (2003) Staging of brain pathology related to sporadic Parkinson's disease. Neurobiol Aging 24:197-211

20. Halliday GM, Li YW, Blumbergs PC, Joh TH, Cotton RGH, Howe PRC, Blessing WW, Geffen LB (1990) Neuropathology of immunohistochemically identified brainstem neurons in Parkinson's disease. Ann Neurol 27:373-385 https:// doi.org/10.1002/ana.410270405

21. Hassani OK, Rymar W, Nguyen KQ, Huo L, Cloutier J-F, Miller FD, Sadikot AF (2020) The noradrenergic system is necessary for survival of vulnerable midbrain dopaminergic neurons: implications for development and Parkinson's disease. Neurobiology of Aging. 85:22-37

22. Rosas HD, Salat DH, Lee SY, Zaleta AK, Pappu V, Fischl B, Greve D, Hevelone N, Hersch SM (2008) Cerebral cortex and the clinical expression of Huntington\&\#039;s disease: complexity and heterogeneity. Brain 131:1057-1068

23. Kassubek J, Juengling FD, Ecker D, Landwehrmeyer GB (2005) Thalamic atrophy in Huntington's disease co-varies with cognitive performance: a morphometric MRI analysis. Cereb Cortex 15:846-853 https://doi.org/10. 1093/cercor/bhh185

24. Heinsen H, Rub U, Gangnus D, Jungkunz G, Bauer M, Ulmar G, Bethke B, Schuler M, Bocker F, Eisenmenger W, Gotz M, Strik M (1996) Nerve cell loss in the thalamic centromedian-parafascicular complex in patients with Huntington's disease. Acta Neuropathol 91:161-168

25. Fujiyama F, Unzai T, Nakamura K, Nomura S, Kaneko T (2006) Difference in organization of corticostriatal and thalamostriatal synapses between patch and matrix compartments of rat neostriatum. Eur J Neurosci 24:2813-2824 https://doi.org/10.1111/j.1460-9568.2006.05177.x

26. Raju DV, Shah DJ, Wright TM, Hall RA, Smith Y (2006) Differential synaptology of vGluT2-containing thalamostriatal afferents between the patch and matrix compartments in rats. J Comp Neurol 499:231-243 https://doi.org/10.1002/cne.21099 
27. Sadikot AF, Parent A, Smith Y, Bolam JP (1992) Efferent connections of the centromedian and parafascicular thalamic nuclei in the squirrel monkey: a light and electron microscopic study of the thalamostriatal projection in relation to striatal heterogeneity. J Comp Neurol 320:228-242 https://doi. org/10.1002/cne.903200207

28. Lapper SR, Bolam JP (1992) Input from the frontal cortex and the parafascicular nucleus to cholinergic interneurons in the dorsal striatum of the rat. Neuroscience 51:533-545

29. Rudkin TM, Sadikot AF (1999) Thalamic input to parvalbuminimmunoreactive GABAergic interneurons: organization in normal striatum and effect of neonatal decortication. Neuroscience 88:1165-1175

30. Sidibe M, Smith Y (1999) Thalamic inputs to striatal interneurons in monkeys: synaptic organization and co-localization of calcium binding proteins. Neuroscience 89:1189-1208

31. Deng YP, Reiner A (2016) Cholinergic interneurons in the Q140 knockin mouse model of Huntington's disease: reductions in dendritic branching and thalamostriatal input. J Comp Neurol 524:3518-3529 https://doi.org/10. 1002/cne.24013

32. Deng YP, Wong T, Bricker-Anthony C, Deng B, Reiner A (2013) Loss of corticostriatal and thalamostriatal synaptic terminals precedes striatal projection neuron pathology in heterozygous Q140 Huntington's disease mice. Neurobiol Dis 60:89-107 https://doi.org/10.1016/j.nbd.2013.08.009

33. Mangiarini L, Sathasivam K, Seller M, Cozens B, Harper A, Hetherington C, Lawton M, Trottier Y, Lehrach H, Davies SW, Bates GP (1996) Exon 1 of the $\mathrm{HD}$ gene with an expanded CAG repeat is sufficient to cause a progressive neurological phenotype in transgenic mice. Cell 87:493-506

34. Samadi P, Boutet A, Rymar W, Rawal K, Maheux J, Kvann JC, Tomaszewski M, Beaubien F, Cloutier JF, Levesque D, Sadikot AF (2013) Relationship between BDNF expression in major striatal afferents, striatum morphology and motor behavior in the R6/2 mouse model of Huntington's disease. Genes Brain Behav 12:108-124 https://doi.org/10.1111/j.1601-183X.2012. 00858.x

35. Franklin KBJ, Paxinos G (2008) The mouse brain in stereotaxic coordinates, 3rd edn. Elsevier/Academic Press, Amsterdam ; Boston

36. Sadikot AF, Leung K, Mittal S, Rymar W, Alonso-Vanegas M, Luk KC (2005) Anterograde Trophic Mechanisms Participate in Pattern Formation in the Striatum: A Role for BDNF in Glutamatergic Afferents. In: The basal ganglia VIII. Springer US, Boston, MA, pp 219-228

37. Aoki S, Liu AW, Zucca A, Zucca S, Wickens JR (2015) Role of striatal cholinergic interneurons in set-shifting in the rat. J Neurosci 35:9424-9431 https://doi.org/10.1523/JNEUROSCI.0490-15.2015

38. Wahlsten D (2011) Chapter 4 - designs. In: mouse behavioral testing Academic press, London, pp 53-73. https://doi.org/10.1016/B978-0-12 375674-9.10004-7

39. Bailoo JD, Bohlen MO, Wahlsten D (2010) The precision of video and photocell tracking systems and the elimination of tracking errors with infrared backlighting. J Neurosci Methods 188:45-52 https://doi.org/10.1016/ j.jneumeth.2010.01.035

40. Gundersen HJ, Jensen EB, Kieu K, Nielsen J (1999) The efficiency of systematic sampling in stereology--reconsidered. J Microsc 193:199-211

41. Sadikot AF, Sasseville R (1997) Neurogenesis in the mammalian neostriatum and nucleus accumbens: parvalbumin-immunoreactive GABAergic interneurons. J Comp Neurol 389:193-211

42. Moller A, Strange P, Gundersen HJ (1990) Efficient estimation of cell volume and number using the nucleator and the disector. J Microsc 159:61-71

43. Team RC (2018) R: A language and environment for statistical computing; 2015

44. Wobbrock JO, Findlater L, Gergle D, Higgins JJ (2011) The aligned rank transform for nonparametric factorial analyses using only anova procedures. Paper presented at the proceedings of the SIGCHI conference on human factors in computing systems. Vancouver, BC, Canada

45. Brooks SP, Dunnett SB (2009) Tests to assess motor phenotype in mice: a user\&\#39;s guide. Nat Rev Neurosci 10:519 https://doi.org/10.1038/nrn2652 https://www.nature.com/articles/nrn2652\#supplementary-information

46. Liang CC, Tanabe LM, Jou S, Chi F, Dauer WT (2014) TorsinA hypofunction causes abnormal twisting movements and sensorimotor circuit neurodegeneration. J Clin Invest 124:3080-3092 https://doi.org/10.1172/ $\mathrm{JCl} 72830$

47. Pappas SS, Darr K, Holley SM, Cepeda C, Mabrouk OS, Wong JM, LeWitt TM, Paudel R, Houlden H, Kennedy RT, Levine MS, Dauer WT (2015) Forebrain deletion of the dystonia protein torsinA causes dystonic-like movements and loss of striatal cholinergic neurons. Elife 4:e08352 https://doi.org/10. 7554/eLife.08352

48. Giampa C, Middei S, Patassini S, Borreca A, Marullo F, Laurenti D, Bernardi G, Ammassari-Teule M, Fusco FR (2009) Phosphodiesterase type IV inhibition prevents sequestration of CREB binding protein, protects striatal parvalbumin interneurons and rescues motor deficits in the R6/2 mouse model of Huntington's disease. Eur J Neurosci 29:902-910 https://doi.org/ 10.1111/j.1460-9568.2009.06649.x

49. Bennett BD, Bolam JP (1994) Synaptic input and output of parvalbuminimmunoreactive neurons in the neostriatum of the rat. Neuroscience 62 707-719

50. Bolam JP, Wainer BH, Smith AD (1984) Characterization of cholinergic neurons in the rat neostriatum. A combination of choline acetyltransferase immunocytochemistry, Golgi-impregnation and electron microscopy. Neuroscience 12:711-718

51. Doig NM, Magill PJ, Apicella P, Bolam JP, Sharott A (2014) Cortical and thalamic excitation mediate the multiphasic responses of striatal cholinergic interneurons to motivationally salient stimuli. J Neurosci 34:3101-3117 https://doi.org/10.1523/JNEUROSCI.4627-13.2014

52. Lapper SR, Smith Y, Sadikot AF, Parent A, Bolam JP (1992) Cortical input to parvalbumin-immunoreactive neurones in the putamen of the squirrel monkey. Brain Res 580:215-224

53. Ding JB, Guzman JN, Peterson JD, Goldberg JA, Surmeier DJ (2010) Thalamic gating of corticostriatal signaling by cholinergic interneurons. Neuron 67: 294-307 https://doi.org/10.1016/j.neuron.2010.06.017

54. Tanimura A, Lim SA, Aceves Buendia JJ, Goldberg JA, Surmeier DJ (2016) Cholinergic interneurons amplify Corticostriatal synaptic responses in the Q175 model of Huntington's disease. Front Syst Neurosci 10:102 https://doi. org/10.3389/fnsys.2016.00102

55. Gharami K, Xie Y, An JJ, Tonegawa S, Xu B (2008) Brain-derived neurotrophic factor over-expression in the forebrain ameliorates Huntington's disease phenotypes in mice. J Neurochem 105:369-379 https://doi.org/10.1111/j. 1471-4159.2007.05137.x

56. Xie Y, Hayden MR, Xu B (2010) BDNF overexpression in the forebrain rescues Huntington's disease phenotypes in YAC128 mice. J Neurosci 30: 14708-14718 https://doi.org/10.1523/jneurosci.1637-10.2010

57. Milnerwood AJ, Kaufman AM, Sepers MD, Gladding CM, Zhang L, Wang L, Fan J, Coquinco A, Qiao JY, Lee H, Wang YT, Cynader M, Raymond LA (2012) Mitigation of augmented extrasynaptic NMDAR signaling and apoptosis in cortico-striatal co-cultures from Huntington's disease mice. Neurobiol Dis 48:40-51 https://doi.org/10.1016/j.nbd.2012.05.013

58. Shehadeh J, Fernandes HB, Zeron Mullins MM, Graham RK, Leavitt BR, Hayden MR, Raymond LA (2006) Striatal neuronal apoptosis is preferentially enhanced by NMDA receptor activation in YAC transgenic mouse model of Huntington disease. Neurobiol Dis 21:392-403 https://doi.org/10.1016/j.nbd. 2005.08.001

59. Zeron MM, Hansson $\mathrm{O}$, Chen $\mathrm{N}$, Wellington $\mathrm{CL}$, Leavitt BR, Brundin $\mathrm{P}$, Hayden MR, Raymond LA (2002) Increased sensitivity to N-methyl-Daspartate receptor-mediated excitotoxicity in a mouse model of Huntington's disease. Neuron 33:849-860

60. Ikonomidou C, Stefovska V, Turski L (2000) Neuronal death enhanced by Nmethyl-D-aspartate antagonists. Proc Natl Acad Sci U S A 97:12885-12890 https://doi.org/10.1073/pnas.220412197

61. Hardingham GE, Bading H (2010) Synaptic versus extrasynaptic NMDA receptor signalling: implications for neurodegenerative disorders. Nat Rev Neurosci 11:682-696 https://doi.org/10.1038/nrn2911

62. Kaufman AM, Milnerwood AJ, Sepers MD, Coquinco A, She K, Wang L, Lee H, Craig AM, Cynader M, Raymond LA (2012) Opposing Roles of synaptic and Extrasynaptic NMDA receptor signaling in Cocultured striatal and cortical neurons. J Neurosci 32:3992 https://doi.org/10.1523/JNEUROSCI. 4129-11.2012

63. Zuccato C, Cattaneo E (2009) Brain-derived neurotrophic factor in neurodegenerative diseases. Nat Rev Neurol 5:311 https://doi.org/10.1038/ nrneurol.2009.54

64. Parievsky A, Moore C, Kamdjou T, Cepeda C, Meshul CK, Levine MS (2017) Differential electrophysiological and morphological alterations of thalamostriatal and corticostriatal projections in the R6/2 mouse model of Huntington's disease. Neurobiol Dis 108:29-44. https://doi.org/10.1016/j.nbd. 2017.07.020

65. Tanimura A, Du Y, Kondapalli J, Wokosin DL, Surmeier DJ (2019) Cholinergic interneurons amplify Thalamostriatal excitation of striatal indirect pathway 
neurons in Parkinson's disease models. Neuron 101:444-458.e446. https:// doi.org/10.1016/j.neuron.2018.12.004

66. Ellender TJ, Harwood J, Kosillo P, Capogna M, Bolam JP (2013) Heterogeneous properties of central lateral and parafascicular thalamic synapses in the striatum. J Physiol 591:257-272 https://doi.org/10.1113/ jphysiol.2012.245233

67. Kolodziejczyk K, Raymond LA (2016) Differential changes in thalamic and cortical excitatory synapses onto striatal spiny projection neurons in a Huntington disease mouse model. Neurobiol Dis 86:62-74 https://doi.org/ 10.1016/j.nbd.2015.11.020

68. Conner JM, Lauterborn JC, Yan Q, Gall CM, Varon S (1997) Distribution of brain-derived neurotrophic factor (BDNF) protein and mRNA in the norma adult rat CNS: evidence for anterograde axonal transport. J Neurosci 17: 2295-2313

69. Bradfield LA, Balleine BW (2017) Thalamic control of Dorsomedial striatum regulates internal state to guide goal-directed action selection. J Neurosci 37:3721-3733 https://doi.org/10.1523/JNEUROSCI.3860-16.2017

70. Bradfield LA, Bertran-Gonzalez J, Chieng B, Balleine BW (2013) The thalamostriatal pathway and cholinergic control of goal-directed action: interlacing new with existing learning in the striatum. Neuron 79:153-166 https://doi.org/10.1016/j.neuron.2013.04.039

71. Gernert M, Hamann M, Bennay M, Loscher W, Richter A (2000) Deficit of striatal parvalbumin-reactive GABAergic interneurons and decreased basal ganglia output in a genetic rodent model of idiopathic paroxysmal dystonia. J Neurosci 20:7052-7058

72. Gonzales KK, Smith Y (2015) Cholinergic interneurons in the dorsal and ventral striatum: anatomical and functional considerations in normal and diseased conditions. Ann N Y Acad Sci 1349:1-45 https://doi.org/10.1111/ nyas. 12762

73. Kimura M, Minamimoto T, Matsumoto N, Hori Y (2004) Monitoring and switching of cortico-basal ganglia loop functions by the thalamo-striatal system. Neurosci Res 48:355-360. https://doi.org/10.1016/j.neures.2003.12. 002

74. Nakano Y, Karube F, Hirai Y, Kobayashi K, Hioki H, Okamoto S, Kameda H, Fujiyama $F$ Parvalbumin-producing striatal interneurons receive excitatory inputs onto proximal dendrites from the motor thalamus in male mice. J Neurosci Res. https://doi.org/10.1002/jnr.24214

75. Nanda B, Galvan A, Smith Y, Wichmann T (2009) Effects of stimulation of the centromedian nucleus of the thalamus on the activity of striatal cells in awake rhesus monkeys. Eur J Neurosci 29:588-598 https://doi.org/10.1111/j. 1460-9568.2008.06598.x

76. Tepper JM, Bolam JP (2004) Functional diversity and specificity of neostriatal interneurons. Curr Opin Neurobiol 14:685-692 https://doi.org/10.1016/j. conb.2004.10.003

77. Kawaguchi Y (1992) Large aspiny cells in the matrix of the rat neostriatum in vitro: physiological identification, relation to the compartments and excitatory postsynaptic currents. J Neurophysiol 67:1669-1682

78. Penny GR, Wilson CJ, Kitai ST (1988) Relationship of the axonal and dendritic geometry of spiny projection neurons to the compartmental organization of the neostriatum. J Comp Neurol 269:275-289 https://doi.org/10.1002/cne. 902690211

79. Ramanathan S, Hanley JJ, Deniau JM, Bolam JP (2002) Synaptic convergence of motor and somatosensory cortical afferents onto GABAergic interneurons in the rat striatum. J Neurosci 22:8158-8169

80. Harrington K, Kowall N (1991) Parvalbumin immunoreactive neurons resist degeneration in Huntingtons-disease striatum. In: Journal of Neuropathology and Experimental Neurology, vol 3. AMER ASSN NEUROPATHOLOGISTS INC, LAWRENCE, pp 309-309

81. Simmons DA, Belichenko NP, Yang T, Condon C, Monbureau M, Shamloo M, Jing D, Massa SM, Longo FM (2013) A Small Molecule TrkB Ligand Reduces Motor Impairment and Neuropathology in R6/2 and BACHD Mouse Models of Huntington\&\#039;s Disease. J Neurosci 33:18712 https://doi.org/10.1523/ JNEUROSCI.1310-13.2013

82. Guo Q, Wang D, He X, Feng Q, Lin R, Xu F, Fu L, Luo M (2015) Whole-brain mapping of inputs to projection neurons and cholinergic interneurons in the dorsal striatum. PLoS One 10:e0123381 https://doi.org/10.1371/journal. pone.0123381

83. Wilson CJ, Chang HT, Kitai ST (1990) Firing patterns and synaptic potentials of identified giant aspiny interneurons in the rat neostriatum. J Neurosci 10:508-519

84. Smith $\mathrm{R}$, Chung $\mathrm{H}$, Rundquist $\mathrm{S}$, Maat-Schieman MLC, Colgan L, Englund $\mathrm{E}$, Liu Y-J, Roos RAC, Faull RLM, Brundin P, Li J-Y (2006) Cholinergic neuronal defect without cell loss in Huntington's disease. Hum Mol Genet 15:31193131 https://doi.org/10.1093/hmg/ddl252

85. Suzuki M, Desmond TJ, Albin RL, Frey KA (2001) Vesicular neurotransmitter transporters in Huntington's disease: initial observations and comparison with traditional synaptic markers. Synapse 41:329-336 https://doi.org/10. 1002/syn.1089

86. Farrar AM, Callahan JW, Abercrombie ED (2011) Reduced striatal acetylcholine efflux in the R6/2 mouse model of Huntington's disease: an examination of the role of altered inhibitory and excitatory mechanisms. Exp Neurol 232:119-125 https://doi.org/10.1016/j.expneurol.2011.08.010

87. Picconi B, Passino E, Sgobio C, Bonsi P, Barone I, Ghiglieri V, Pisani A, Bernardi G, Ammassari-Teule M, Calabresi P (2006) Plastic and behavioral abnormalities in experimental Huntington's disease: a crucial role for cholinergic interneurons. Neurobiol Dis 22:143-152 https://doi.org/10.1016/j. nbd.2005.10.009

88. Vetter JM, Jehle T, Heinemeyer J, Franz P, Behrens PF, Jackisch R, Landwehrmeyer GB, Feuerstein TJ (2003) Mice transgenic for exon 1 of Huntington's disease: properties of cholinergic and dopaminergic presynaptic function in the striatum. J Neurochem 85:1054-1063

89. Tallaksen-Greene SJ, Kaatz KW, Romano C, Albin RL (1998) Localization of mGluR1a-like immunoreactivity and mGluR5-like immunoreactivity in identified populations of striatal neurons. Brain Res 780:210-217. https://doi. org/10.1016/S0006-8993(97)01141-4

90. Kuppenbender KD, Standaert DG, Feuerstein TJ, Penney JB Jr, Young AB, Landwehrmeyer GB (2000) Expression of NMDA receptor subunit mRNAs in neurochemically identified projection and interneurons in the human striatum. J Comp Neurol 419:407-421

91. Landwehrmeyer G, Standaert D, Testa C, Penney J, Young A (1995) NMDA receptor subunit mRNA expression by projection neurons and interneurons in rat striatum. J Neurosci 15:5297-5307 https://doi.org/10.1523/jneurosci.1507-05297.1995

92. Standaert DG, Friberg IK, Landwehrmeyer GB, Young AB, Penney JB Jr (1999) Expression of NMDA glutamate receptor subunit mRNAs in neurochemically identified projection and interneurons in the striatum of the rat. Brain Res Mol Brain Res 64:11-23

93. Martinez-Serrano A, Hantzopoulos PA, Bjorklund A (1996) Ex vivo gene transfer of brain-derived neurotrophic factor to the intact rat forebrain: neurotrophic effects on cholinergic neurons. Eur J Neurosci 8:727-735

94. Larsson E, Nanobashvili A, Kokaia Z, Lindvall O (1999) Evidence for neuroprotective effects of endogenous brain-derived neurotrophic factor after global forebrain ischemia in rats. J Cereb Blood Flow Metab 19:12201228 https://doi.org/10.1097/00004647-199911000-00006

95. Lucidi-Phillipi CA, Gage FH, Shults CW, Jones KR, Reichardt LF, Kang UJ (1995) Brain-derived neurotrophic factor-transduced fibroblasts: production of BDNF and effects of grafting to the adult rat brain. J Comp Neurol 354: 361-376 https://doi.org/10.1002/cne.903540306

96. Richardson PJ, Dixon AK, Lee K, Bell Ml, Cox PJ, Williams R, Pinnock RD, Freeman TC (2000) Correlating physiology with gene expression in striatal cholinergic neurones. J Neurochem 74:839-846

97. Steininger TL, Wainer BH, Klein R, Barbacid M, Palfrey HC (1993) High-affinity nerve growth factor receptor (Trk) immunoreactivity is localized in cholinergic neurons of the basal forebrain and striatum in the adult rat brain. Brain Res 612:330-335

98. Fusco FR, Zuccato C, Tartari M, Martorana A, De March Z, Giampa C, Cattaneo E, Bernardi G (2003) Co-localization of brain-derived neurotrophic factor (BDNF) and wild-type huntingtin in normal and quinolinic acidlesioned rat brain. Eur J Neurosci 18:1093-1102

99. Altar CA, Cai N, Bliven T, Juhasz M, Conner JM, Acheson AL, Lindsay RM, Wiegand SJ (1997) Anterograde transport of brain-derived neurotrophic factor and its role in the brain. Nature 389:856-860 https://doi.org/10.1038/ 39885

100. Lein ES, Hawrylycz MJ, Ao N, Ayres M, Bensinger A, Bernard A, Boe AF, Boguski MS, Brockway KS, Byrnes EJ (2007) Genome-wide atlas of gene expression in the adult mouse brain. Nature 445:168

101. Malkovska I, Kernie SG, Parada LF (2006) Differential expression of the four untranslated BDNF exons in the adult mouse brain. J Neurosci Res 83:211221 https://doi.org/10.1002/jnr.20728

102. Schmidt-Kastner $R$, Wetmore C, Olson L (1996) Comparative study of BRAINderived NEUROTROPHIC factor messenger RNA and protein at the cellular level suggests multiple ROLES in hippocampus, striatum and cortex. Neuroscience 74:161-183. https://doi.org/10.1016/0306-4522(96)00093-0 
103. Zuccato C, Ciammola A, Rigamonti D, Leavitt BR, Goffredo D, Conti L, MacDonald ME, Friedlander RM, Silani V, Hayden MR, Timmusk T, Sipione S, Cattaneo E (2001) Loss of Huntingtin-mediated BDNF gene transcription in Huntington's disease. Science 293:493-498 https://doi. org/10.1126/science.1059581

104. Ayloo S, Guedes-Dias P, Ghiretti AE, Holzbaur ELF (2017) Dynein efficiently navigates the dendritic cytoskeleton to drive the retrograde trafficking of BDNF/TrkB signaling endosomes. Mol Biol Cell 28:2543-2554 https://doi.org/ 10.1091/mbc.e17-01-0068

105. Braunstein KE, Eschbach J, Ròna-Vörös K, Soylu R, Mikrouli E, Larmet Y, René F, De Aguilar J-LG, Loeffler J-P, Müller H-P, Bucher S, Kaulisch T, Niessen HG, Tillmanns J, Fischer K, Schwalenstöcker B, Kassubek J, Pichler B, Stiller D, Petersen $\AA$, Ludolph AC, Dupuis L (2010) A point mutation in the dynein heavy chain gene leads to striatal atrophy and compromises neurite outgrowth of striatal neurons. Hum Mol Genet 19:4385-4398 https://doi. org/10.1093/hmg/ddq361

106. Cohen MS, Bas Orth C, Kim HJ, Jeon NL, Jaffrey SR (2011) Neurotrophinmediated dendrite-to-nucleus signaling revealed by microfluidic compartmentalization of dendrites. Proc Natl Acad Sci U S A 108:1124611251 https://doi.org/10.1073/pnas.1012401108

107. Kononenko NL, Claßen GA, Kuijpers M, Puchkov D, Maritzen T, Tempes A, Malik AR, Skalecka A, Bera S, Jaworski J, Haucke V (2017) Retrograde transport of TrkB-containing autophagosomes via the adaptor AP-2 mediates neuronal complexity and prevents neurodegeneration. Nat Commun 8:14819-14819 https://doi.org/10.1038/ncomms14819

108. Liot G, Zala D, Pla P, Mottet G, Piel M, Saudou F (2013) Mutant Huntingtin alters retrograde transport of TrkB receptors in striatal dendrites. J Neurosci 33:6298 https://doi.org/10.1523/JNEUROSCI.2033-12.2013

109. Moya-Alvarado G, Gonzalez A, Stuardo N, Bronfman FC (2018) Brain-derived Neurotrophic factor (BDNF) regulates Rab5-positive early endosomes in hippocampal neurons to induce dendritic branching. Front Cell Neurosci. https://doi.org/10.3389/fncel.2018.00493

110. Sasi M, Vignoli B, Canossa M, Blum R (2017) Neurobiology of local and intercellular BDNF signaling. Pflugers Arch - Eur J Physiol 469:593-610 https://doi.org/10.1007/s00424-017-1964-4

111. del Toro D, Canals JM, Gines S, Kojima M, Egea G, Alberch J (2006) Mutant huntingtin impairs the post-Golgi trafficking of brain-derived neurotrophic factor but not its Val66Met polymorphism. J Neurosci 26:12748-12757 https://doi.org/10.1523/jneurosci.3873-06.2006

112. Gauthier LR, Charrin BC, Borrell-Pages $M$, Dompierre JP, Rangone $H$, Cordelieres FP, De Mey J, MacDonald ME, Lessmann V, Humbert S, Saudou F (2004) Huntingtin controls neurotrophic support and survival of neurons by enhancing BDNF vesicular transport along microtubules. Cell 118:127138 https://doi.org/10.1016/j.cell.2004.06.018

113. Numakawa T, Suzuki S, Kumamaru E, Adachi N, Richards M, Kunugi H (2010) BDNF function and intracellular signaling in neurons. Histol Histopathol 25: 237-258 https://doi.org/10.14670/hh-25.237

114. Zheng J, Shen WH, Lu TJ, Zhou Y, Chen Q, Wang Z, Xiang T, Zhu YC, Zhang C, Duan S, Xiong ZQ (2008) Clathrin-dependent endocytosis is required for TrkB-dependent Akt-mediated neuronal protection and dendritic growth. J Biol Chem 283:13280-13288 https://doi.org/10.1074/jbc.M709930200

115. Fusco FR, Chen Q, Lamoreaux WJ, Figueredo-Cardenas G, Jiao Y, Coffman JA, Surmeier DJ, Honig MG, Carlock LR, Reiner A (1999) Cellular localization of Huntingtin in striatal and cortical neurons in rats: lack of correlation with neuronal vulnerability in Huntington's disease. J Neurosci 19:1189-1202

116. Marsden C (1976) Dystonia: the spectrum of the disease. Research publications-Association for Research in Nervous and Mental Disease 55: 351-367

117. Neychev VK, Gross RE, Lehéricy S, Hess EJ, Jinnah HA (2011) The functional neuroanatomy of dystonia. Neurobiol Dis 42:185-201 https://doi.org/10. 1016/j.nbd.2011.01.026

118. Phukan J, Albanese A, Gasser T, Warner T (2011) Primary dystonia and dystonia-plus syndromes: clinical characteristics, diagnosis, and pathogenesis. Lancet Neurol 10:1074-1085 https://doi.org/10.1016/s14744422(11)70232-0

119. LeDoux MS, Brady KA (2003) Secondary cervical dystonia associated with structural lesions of the central nervous system. Mov Disord 18:60-69 https://doi.org/10.1002/mds.10301

120. Lee MS, Marsden CD (1994) Movement disorders following lesions of the thalamus or subthalamic region. Mov Disord 9:493-507 https://doi.org/10. 1002/mds.870090502
121. Marsden CD, Obeso JA, Zarranz JJ, Lang AE (1985) The anatomical basis of symptomatic HEMIDYSTONIA. Brain 108:463-483 https://doi.org/10.1093/ brain/108.2.463

122. Meissner I, Sapir S, Kokmen E, Stein SD (1987) The paramedian diencephalic syndrome: a dynamic phenomenon. Stroke 18:380-385

123. Rumbach L, Barth P, Costaz A, Mas J (1995) Hemidystonia consequent upon ipsilateral vertebral artery occlusion and cerebellar infarction. Mov Disord 10: 522-525 https://doi.org/10.1002/mds.870100423

124. Zadro I, Brinar W, Barun B, Ozretic D, Habek M (2008) Cervical dystonia due to cerebellar stroke. Mov Disord 23:919-920 https://doi.org/10.1002/ mds. 21981

125. Wilson BK, Hess EJ (2013) Animal models for dystonia. Mov Disord 28:982989 https://doi.org/10.1002/mds.25526

126. Eskow Jaunarajs KL, Bonsi P, Chesselet MF, Standaert DG, Pisani A (2015) Striatal cholinergic dysfunction as a unifying theme in the pathophysiology of dystonia. Prog Neurobiol 127-128:91-107. https://doi.org/10.1016/j. pneurobio.2015.02.002

127. Bao L, Patel JC, Walker RH, Shashidharan P, Rice ME (2010) Dysregulation of striatal dopamine release in a mouse model of dystonia. J Neurochem 114: 1781-1791 https://doi.org/10.1111/j.1471-4159.2010.06890.x

128. Pisani A, Martella G, Tscherter A, Bonsi P, Sharma N, Bernardi G, Standaert DG (2006) Altered responses to dopaminergic D2 receptor activation and $\mathrm{N}$-type calcium currents in striatal cholinergic interneurons in a mouse model of DYT1 dystonia. Neurobiol Dis 24:318-325. https://doi.org/10.1016/j. $\mathrm{nbd}$.2006.07.006

129. Sciamanna G, Hollis R, Ball C, Martella G, Tassone A, Marshall A, Parsons D, Li X, Yokoi F, Zhang L, Li Y, Pisani A, Standaert DG (2012) Cholinergic dysregulation produced by selective inactivation of the dystonia-associated protein torsinA. Neurobiol Dis 47:416-427 https:// doi.org/10.1016/j.nbd.2012.04.015

130. Sciamanna G, Tassone A, Mandolesi G, Puglisi F, Ponterio G, Martella G, Madeo G, Bernardi G, Standaert DG, Bonsi P, Pisani A (2012) Cholinergic dysfunction alters synaptic integration between thalamostriatal and corticostriatal inputs in DYT1 dystonia. J Neurosci 32:11991-12004 https:// doi.org/10.1523/JNEUROSCI.0041-12.2012

131. Brown HD, Baker PM, Ragozzino ME (2010) The parafascicular thalamic nucleus concomitantly influences behavioral flexibility and dorsomedial striatal acetylcholine output in rats. J Neurosci 30:14390-14398 https://doi. org/10.1523/JNEUROSCI.2167-10.2010

132. Threlfell S, Lalic T, Platt NJ, Jennings KA, Deisseroth K, Cragg SJ (2012) Striatal dopamine release is triggered by synchronized activity in cholinergic interneurons. Neuron 75:58-64 https://doi.org/10.1016/j.neuron.2012.04.038

133. Matsumoto N, Minamimoto T, Graybiel AM, Kimura M (2001) Neurons in the thalamic CM-Pf complex supply striatal neurons with information about behaviorally significant sensory events. J Neurophysiol 85:960-976

134. Dresel C, Li Y, Wilzeck V, Castrop F, Zimmer C, Haslinger B (2014) Multiple changes of functional connectivity between sensorimotor areas in focal hand dystonia. J Neurol Neurosurg Psychiatry 85:1245-1252 https://doi.org/ 10.1136/jnnp-2013-307127

135. Hutchinson M, Nakamura T, Moeller JR, Antonini A, Belakhlef A, Dhawan V, Eidelberg D (2000) The metabolic topography of essential blepharospasm: a focal dystonia with general implications. Neurology 55:673-677

136. Yang J, Luo C, Song W, Guo X, Zhao B, Chen X, Huang X, Gong Q, Shang HF (2014) Diffusion tensor imaging in blepharospasm and blepharospasmoromandibular dystonia. J Neurol 261:1413-1424 https://doi.org/10.1007/ s00415-014-7359-y

137. Rees EM, Farmer R, Cole JH, Haider S, Durr A, Landwehrmeyer B, Scahill Rl, Tabrizi SJ, Hobbs NZ (2014) Cerebellar abnormalities in Huntington's disease: a role in motor and psychiatric impairment? Mov Disord 29:16481654 https://doi.org/10.1002/mds.25984

138. Rub U, Hoche F, Brunt ER, Heinsen H, Seidel K, Del Turco D, Paulson HL, Bohl J, von Gall C, Vonsattel JP, Korf HW, den Dunnen WF (2013) Degeneration of the cerebellum in Huntington's disease (HD): possible relevance for the clinical picture and potential gateway to pathological mechanisms of the disease process. Brain Pathol 23:165-177 https://doi.org/ 10.1111/j.1750-3639.2012.00629.x

139. Dougherty SE, Reeves JL, Lesort M, Detloff PJ, Cowell RM (2013) Purkinje cell dysfunction and loss in a knock-in mouse model of Huntington disease. Exp Neurol 240:96-102 https://doi.org/10.1016/j.expneurol.2012.11.015

140. Dougherty SE, Reeves JL, Lucas EK, Gamble KL, Lesort M, Cowell RM (2012) Disruption of Purkinje cell function prior to huntingtin accumulation and 
cell loss in an animal model of Huntington disease. Exp Neurol 236:171-178 https://doi.org/10.1016/j.expneurol.2012.04.015

141. Hoshi E, Tremblay L, Féger J, Carras PL, Strick PL (2005) The cerebellum communicates with the basal ganglia. Nat Neurosci 8:1491 https://doi.org/ 10.1038/nn1544 https://www.nature.com/articles/nn1544\#supplementaryinformation

142. Melik-Musyan AB, Fanardjyan W (1998) Projections of the central cerebellar nuclei to the intralaminar thalamic nuclei in cats. Neurophysiology 30:39-47 https://doi.org/10.1007/BF02463111

143. Pelzer EA, Melzer C, Timmermann L, von Cramon DY, Tittgemeyer M (2017) Basal ganglia and cerebellar interconnectivity within the human thalamus. Brain Struct Funct 222:381-392 https://doi.org/10.1007/s00429-016-1223-z

144. Edalatmanesh MA, Nikfarjam H, Moghadas M, Haddad-Mashadrizeh A, Robati R, Hashemzadeh MR (2014) Histopathological and behavioral assessment of toxin-produced cerebellar lesion: a potent model for cell transplantation studies in the cerebellum. Cell J 16:325-334

\section{Publisher's Note}

Springer Nature remains neutral with regard to jurisdictional claims in published maps and institutional affiliations.

Ready to submit your research? Choose BMC and benefit from:

- fast, convenient online submission

- thorough peer review by experienced researchers in your field

- rapid publication on acceptance

- support for research data, including large and complex data types

- gold Open Access which fosters wider collaboration and increased citations

- maximum visibility for your research: over $100 \mathrm{M}$ website views per year

At BMC, research is always in progress.

Learn more biomedcentral.com/submissions 